\title{
EL DEFENSOR DEL PUEBLO LATINOAMERICANO COMO INSTITUCIÓN INDEPENDIENTE DE PROMOCIÓN Y PROTECCIÓN DE LOS DERECHOS HUMANOS: REFERENCIA ESPECIAL A LA SITUACIÓN ACTUAL EN CHILE
}

\author{
GonZalo Aguilar Cavallo* \\ RÉBECCA STEWARD ${ }^{* *}$
}

RESUMEN: Este artículo sostiene que la institución del Defensor del Pueblo forma parte del constitucionalismo contemporáneo. El Defensor del Pueblo es una institución nacional de derechos humanos en el sentido de los denominados "Principios de París". Para cumplir con su rol de promotor y protector de los derechos humanos, el Defensor del Pueblo debe interactuar con los mecanismos nacionales e internacionales de protección de los derechos humanos de manera dinámica y creativa. Este trabajo examina dicha interacción a la luz de la experiencia iberoamericana y del análisis crítico del proyecto que crea el Defensor de las Personas en Chile.

Palabras Clave: Defensor del Pueblo - Derechos Humanos Derecho Internacional de los Derechos Humanos - Estado de derecho Acceso a la justicia - Bien común.

\section{THE LATIN-AMERICAN OMBUDSMAN AS AN INDEPENDENT Institution of Promotion and Protection of Human RightS: SPECIAL REFERENCE TO THE CURRENT SituATION IN CHILE}

ABSTRACT: This article argues that the institution of Ombudsman is part of the contemporary constitutionalism. The Ombudsman is a national human rights institution in the sense of "Paris Principles". The Ombudsman

Profesor de Derecho Internacional Público y Derechos Humanos de la Universidad de Talca, Doctor en Derecho, MA en Relaciones Internacionales y LLM en Derechos Humanos y Derecho Humanitario. Centro de Estudios Constitucionales, Universidad de Talca (Chile). Correo electrónico: gaguilar@utalca.cl

- Consultora de UNICEF, Abogada especialista en derechos humanos, LLM in International Human Rights Law. Correo electrónico: rebsteward@gmail.com Fecha de recepción: 26 de noviembre de 2008.

Fecha de aprobación: 15 de diciembre de 2008. 
must dynamically and creatively interact with the national and international human rights protection system, in order to play its role in the promotion and protection of human rights. This article examines these interactions in the light of the Latin American experience and the critical analysis of the constitutional reform establishing an Ombudsman in Chile.

KEY WORDS: Ombudsman - Human Rights - International Human Rights Law - Rule of Law - Access to Justice - Common Good.

SUMARIO: Introducción. I. Los modelos de Ombudsman o Defensorias del Pueblo. 1.1. La aparición histórica de la institución y su influencia escandinava. 1.2. El modelo iberoamericano: análisis comparado actual. II. El rol del defensor del pueblo en la promoción y protección de los derechos humanos. 2.1. Acceso a la justicia. 2.2. Interacciones: complementariedad y tensiones con los mecanismos nacionales, regionales e internacionales de promoción y protección de derechos humanos. III. El caso chileno: un caso atípico en América Latina. 3.1. Denominación. 3.2. Nombramiento. 3.3. Autonomía respecto del gobierno y del parlamento. 3.4. Mandato amplio basado en normas universales de derechos humanos. 3.5. Luces y sombras del caso chileno.

\section{INTRODUCCIÓN}

Hablar de instituciones como el Defensor del Pueblo o en una acepción más universal, el Ombudsman, debería carecer de estímulo y ser desesperanzador. ¿¿Por qué? Porque de alguna manera, aquello que justifica la necesidad de la existencia de un Defensor u Ombudsman es la falta, el error, el abuso, la discrecionalidad abusiva o la ilegalidad en el actuar de la administración del Estado. Esto significa, en último término, que el Estado ha fallado en su tarea constitucional y fundamental de procurar el bien común, o en otras palabras generar las bases para una sociedad que debe ser protegida. En el terreno de los derechos humanos, este fracaso del Estado es mucho más patente sobre todo si consideramos las desastrosas consecuencias que una violación a los derechos humanos puede acarrear, o en situaciones sistemáticas y generalizadas, como el contexto de un sistema dictatorial, si tenemos presente los perniciosos efectos que pueden provocar en la humanidad. Por eso, la comunidad nacional e internacional contemporánea ha ido estableciendo paulatina y progresivamente niveles más elevados de exigencia para el Estado constitucional, social y democrático de derecho, por ejemplo, respecto de los derechos económicos, sociales y culturales vinculados con los desafíos de la equidad y justicia social, de la discriminación y de la pobreza, y en relación con la articulación del binomio desarrollo y protección del medio ambiente. De esta manera, es posible sostener que los compromisos constitucional e in- 
ternacionalmente declarados son los mismos, pero contemporáneamente las exigencias respecto del Estado son más altas. En el caso chileno, no es necesario que la Constitución declare expresamente que el Estado es constitucional, social y democrático de derecho, ya que ello fluye natural e inherentemente del espíritu y de la política constitucional y de lo preceptuado en los artículos 1, 4, 5, 6, 7 y 19 de la Constitución actualmente vigente. En consecuencia, la necesidad de un Defensor u Ombudsman no hace sino evidenciar la falta del Estado en el cumplimiento de sus deberes constitucionales, esto es, en el cumplimiento de su obligación de procurar el bien común y de velar porque todos respeten las condiciones constitucionalmente establecidas para que cada uno alcance su plena autorrealización. Es justamente esta falla o abuso de la Administración la que hizo surgir históricamente la necesidad de establecer esta figura.

El Ombudsman o Defensor del Pueblo suele ser calificado como una Institución Nacional de Derechos Humanos (en adelante INDH). Una Institución Nacional de Derechos Humanos es un "organismo creado por un gobierno en aplicación de la Constitución, o creado por la ley, y cuyas atribuciones en materia de promoción y de protección de los dere-

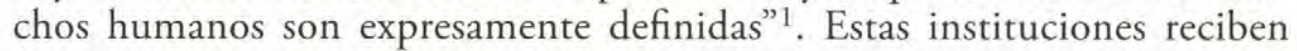
diversas denominaciones en los distintos ordenamientos jurídicos, tales como, Ombudsman, Defensores del Pueblo, Comisionados para los Derechos Humanos, Procuradores de Derechos Humanos, Presidentes de Comisiones Públicas de Derechos Humanos, Proveedores, Raonadores o Médiateur. El Ombudsman o Defensor del Pueblo, que es el término más común en castellano, se ha ido consolidando a lo largo de los ańos como una de las instituciones nacionales de relevancia en la tarea de velar por el cumplimiento de las obligaciones del Estado en materia de derechos humanos. Estas obligaciones del Estado no son otras que respetar, hacer respetar y garantizar los derechos humanos, reconocidos tanto en el orden interno, regional e internacional. En concreto, en el ámbito americano, los Estados partes en la Convención Americana de Derechos Humanos (en adelante la $\mathrm{CADH}$ ), se encuentran obligados a prevenir, investigar y sancionar las violaciones a los derechos humanos ${ }^{2}$. Estas instituciones

1 OACNUDH (1996) Manual sobre la creación y el fortalecimiento de instituciones nacionales para la promoción y protección de los derechos humanos, par. 39, Disponible en: www.ohchr. org/Documents/Publications/training4en.pdf; OANUDH (2004) Los derechos económicos, sociales y culturales: manual para las instituciones nacionales de derechos humanos, Serie de Capacitación Profesional No 12, Nueva York y Ginebra, 2004, www.ohchr.org/Documents/ Publications/training12sp.pdf [Fecha de visita 20 de noviembre 2008].

2 Artículo 1(1) de la CADH dispone que los "Estados partes en esta Convención se comprometen a respetar los derechos y libertades reconocidos en ella y a garantizar su libre y pleno ejercicio a toda persona que esté sujeta a su jurisdicción, sin discriminación alguna por motivos de raza, color, sexo, idioma, religión, opiniones políticas o de cualquier otro índole, origen nacional o social, posición económica, nacimiento o cualquier otra condición social". 
nacionales -valiosos pilares del Estado en el respeto y protección de los derechos humanos- deberían sujetarse a los denominados "Principios de París" que proporcionan un estándar internacional mínimo que asegura la existencia de una institución nacional de derechos humanos efectiva, eficiente e independiente ${ }^{3}$. El Comité de los Derechos del Nińo (en adelante el CDN), entre otros, se ha pronunciado claramente sobre esta obligación de sometimiento a los Principios de París, en cuanto norma mínima a seguir por las instituciones nacionales de derechos humanos ${ }^{4}$.

No ha sido siempre este el rol del Defensor del Pueblo, ni es la característica actual de todos los Ombudsman o Defensores del Pueblo que existen en las diversas regiones del mundo. Claramente, eso sí, el rol que ha tenido siempre ha sido la defensa de los derechos de los individuos. Inicialmente, el Ombudsman o Defensor del Pueblo protegía a los individuos frente al gobierno, por su mala o defectuosa administración, lo que implicaba afectar los derechos de las personas. Posteriormente, esta institución fue evolucionando, conforme se desarrollaban y expandían las expectativas y necesidades de los individuos, comunidades y pueblos. En consecuencia, fundamentalmente, a partir de la segunda mitad del siglo XX, el Ombudsman o Defensor del Pueblo, sobre todo en ciertas regiones del mundo, como por ejemplo en América Latina, comenzó a desarrollar una labor netamente defensora de los derechos humanos de los individuos. Es aquí donde se puede apreciar con claridad la calidad y "raison d'être" de una institución nacional de derechos humanos.

A lo largo de este estudio, nosotros preferiremos usar, por supuesto, el término más frecuente en castellano, a saber, Defensor del Pueblo. Aun cuando debemos hacer presente que en Chile, por la vía del proyecto de reforma constitucional respectivo, se intenta introducir actualmente la denominación de Defensor de las Personas.

Este estudio pretende examinar la estructura y atribuciones del Defensor del Pueblo, a la luz de la experiencia latinoamericana, con el objeto de determinar si esta institución debe poseer la facultad de poner en movimiento los tribunales. Además, nuestra investigación se enfoca en deli-

Principios relativos al estatuto de las instituciones nacionales, Anexo, A/RES/48/134, Asamblea General, 4 de marzo de 1994, 20 de diciembre de 1993; OACNUDH, Folleto informativo $N^{o} 19$, Instituciones Nacionales de Promoción y Protección de los Derechos Humanos, Ginebra, Suiza, www.ohchr.org/Documents/Publications/FactSheet19sp.pdf [Fecha de visita 20 de noviembre 2008]

4 CDN (2002) Observación General No 2, El papel de las instituciones nacionales independientes de derechos humanos en la promoción y protección de los derechos del niño, doc. CRC/ GC/2002/2, de fecha 15 de noviembre, par. 4; ver también: CDN (2002) Observaciones $f$ nales del CDN sobre Argentina, CRC/C/15/Add.187, 9 de Octubre, par.21-22; Observaciones finales del CDN sobre Brasil, CRC/C/15/Add.241, 3 CDN (2004) Noviembre 2004, par.1920; CDN (2006) Observaciones finales del CDN sobre Colombia, CRC/C/COL/CO/3 8 de Junio, par.18-19. 
mitar el rol del Defensor del Pueblo desde el punto de vista de cuál sería el alcance de sus facultades en su relación con, ya sea los órganos de protección del sistema de Naciones Unidas o con los órganos de protección del sistema interamericano, o incluso, con las Organizaciones No Gubernamentales (en adelante ONG) de defensa de los derechos humanos.

Para los efectos de desarrollar nuestro trabajo, abordaremos primeramente un análisis somero de los distintos modelos de Ombudsman o Defensores del Pueblo a fin de extraer la filosofía y orientación que se encuentra detrás de estos modelos (II). En un segundo lugar, analizaremos el papel dinámico que funcional e institucionalmente puede jugar el Defensor del Pueblo en la promoción y protección de los derechos humanos a través de las interacciones con los mecanismos de protección de estos derechos (III). Finalmente, examinaremos, con una visión crítica, los rasgos más distintivos del proyecto de reforma constitucional en Chile (IV).

\section{Los modelos de OMbudsman o Defensorías del Pueblo}

\section{La aparición histórica de la institución y su influencia escan- dinava}

Desde el punto de vista clásico, Islas Colín describe el Ombudsman como un "órgano autónomo cuyo titular, designado por el Poder Legislativo o por el Ejecutivo, o por ambos, tiene como función la vigilancia de la actividad de la administración, la recepción de quejas de los administrados en contra del funcionamiento de los servicios administrativos; él interviene para resolver las controversias en los plazos más breves, investiga para verificar la lesión a los derechos de los administrados y en vista de los resultados de las mismas dirige recomendaciones a las autoridades administrativas a efectos de restablecer las prerrogativas de los administrados" 5 .

Históricamente, la noción de un individuo, cuerpo o institución independiente del gobierno capaz de controlar los abusos o excesos de poder provenientes de una institución pública, u originados en una mala praxis, en el contexto de una administración burocrática, se encuentra presente desde la Antigüedad. Así, como señala Alarcón, en la época de los romanos, el tribuni plebes fue establecido como parte de la Constitución de la República romana para proteger al pueblo de los abusos de la

5 Islas Colin, Alfredo e Islas Colin, Marco Antonio (2007). "El Ombudsman: control no jurisdiccional y protección de derechos humanos". En Cisneros Farías, Germán; Fernández Ruiz, Jorge y López Olrvera, Miguel Alejandro (Coord.). Ombudsman local. Segundo Congreso Iberoamericano de Derecho Administrativo. México: Instituto de Investigaciones Jurídicas, UNAM, pp. 179-205, p. 179. 
burocracia gubernamental ${ }^{6}$. Los suecos luego imitaron la figura romana, y en los primeros ańos de 1700 , el Ombudsman era nombrado por el Rey para supervisar a sus ministros y otros oficiales. En efecto, "Carlos XII -empeñado en la reconstrucción del imperio que lo llevó a estar fuera del país por doce ańos guerreando- percibió la necesidad de designar a un supremo representante del Rey para que vigilara a los funcionarios del gobierno en su ausencia" 7 . Posteriormente, la institución evolucionó hacia un cuerpo administrativo nombrado por el Parlamento - un Comisionado Parlamentario- para proteger los individuos contra los excesos de la administración ${ }^{8}$. Así, en la Constitución sueca de 1809 se creó el justitieombudsman, "un oficial encargado de monitorear las acciones de los funcionarios suecos para asegurarse que las leyes fueran administradas apropiadamente" ". Tal como ha señalado Green y Eisner, Ombudsman es un término sueco que traduce casi literalmente la expresión "intermediario" o "ir mediando" 10 . Por su parte, Islas Colín, señala algo muy similar, en el sentido de que la palabra "Ombudsman significa, gramaticalmente hablando 'aquel que habla por otro'; esto es, el representante, el portavoz del ciudadano, aquel que está destinado a jugar un papel de intermediario entre el ciudadano y los poderes públicos"11.

El Defensor del Pueblo latinoamericano se inspira de la figura del Ombudsman contemplada en la Constitución sueca de $1809^{12}$. En las últimas décadas, esta institución se ha extendido por muchos países del mundo entero, debiéndose destacar en este trabajo, la fuerte presencia de esta figura en el ámbito latinoamericano. Paralelamente al modelo iberoamericano, se plantean otros modelos de Ombudsman o Defensores del Pueblo que se alejan un poco de la tarea contemporáneamente encargada a esta institución, pero que responde más bien a la fórmula original escandinava del Ombudsman. En esta línea se encuentra precisamente el

Alarcón, Arthur L. (2007). "A Prescription for California's Ailing Inmate Treatment System: An Independent Corrections Ombudsman". Hastings Law Journal, $\mathrm{N}^{\circ} 58$, pp. 591621, p. 597.

7 MonTı, Eduardo Jorge. “El Ombudsman: ¿̨Por qué? y ¿̨Para qué?”. Verba Iustitiae, Revista de la Facultad de Derecho, Ciencias Políticas y Sociales, Universidad de Morón, Año X, No 20, p. 37.

Green, Mark y Eisner, Laurel W. (1998): "The Public Advocate for New York City: An Analysis of the Country's Only Elected Ombudsman". New York Law School Law Review, $\mathrm{N}^{\circ}$ 42, pp. 1093-1161, p. 1104. Alarcón, Arthur L., (2007). 597.

10 Green, Mark y Eisner, Laurel W. (1998). 1104; Kuta, Christina M. (2003). "Universities, Corporations and States use them - Now It's Time to Protect them: an Analysis of the Public and Private Sector Ombudsman and the Continued Need for a Privileged Relationship". Southern Illinois University Law Journal, N ${ }^{\circ} 27$, pp. 389-412, p. 389. Islas Colin, Alfredo e Islas Colin, Marco Antonio (2007) 179-205.

12 Pérez Calvo, Alberto (1996): "Artículo 54: El defensor del pueblo". En Alzaga Villaamil, Oscar (Coord.). Comentarios a la Constitución Española. Tomo IV. Madrid: Edersa, 2a edición, pp. 531-579, p. 534. 
Ombudsman europeo creado en el seno de la Unión Europea quien se encarga de enfrentar quejas o denuncias provenientes de ciudadanos individuales o compañías respecto de la mala administración de parte de las instituciones públicas ${ }^{13}$.

El Ombudsman, bajo este modelo de funciones, tiene como objetivo clave, estimular y promover la buena administración pública. La independencia del Ombudsman es vital para el éxito de su misión. Un Ombudsman independiente aportaría credibilidad y transparencia a la administración ya que ayudaría a restaurar la confianza pública en el sistema. Por lo demás, un Ombudsman con autonomía e independencia y con un mandato legislativo claro para recibir, investigar y, si es posible, resolver las quejas de individuos, asociaciones o comunidades, sin duda que contribuiría a mejorar el acceso a la justicia y, además, a reducir los enormes costos económicos y en tiempo y recursos derivados de los litigios ${ }^{14}$. En este sentido, en el orden de la errónea, defectuosa o mala administración pública, el Ombudsman actuaría como una especie de mediador y se configuraría como un órgano eficaz tanto para mejorar el acceso a la justicia y amparar a los individuos en sus derechos como para asegurar una buena y adecuada administración pública. En este sentido, coincidimos absolutamente con las ideas de Anderson cuando seńala que el Ombudsman simboliza más el uso de la razón y persuasión moral que de la fuerza ${ }^{15}$.

En este contexto, el propio Ombudsman europeo ha proporcionado una muy sintética definición de mala administración. Así, hay mala administración, en el ámbito de las instituciones públicas, cuando un órgano público no actúa de conformidad con una norma o un principio legamente vinculante para él ${ }^{16}$. Bajo esta perspectiva, la función del Ombudsman se reduce prácticamente a un mecanismo efectivo de solución de controversias entre particulares y la administración pública ocasionadas por la mala administración. De acuerdo con Pliakos, podemos encontrarnos frente a tres tipos de mala administración: 1) ilegalidad de una acción administrativa de naturaleza decisional; 2) falta de jurisdicción, vicio de forma, contravención de los tratados u otra disposición relacionada con su aplicación, y mal uso del poder; y 3) abuso de discreción ${ }^{17}$. Desde el

13 Más información disponible en: http://ombudsman.europa.eu/home/es/default.htm

14 Alarcón, Arthur L. (2007). 592.

15 "The ombudsman symbol lays the use of reason and moral persuasion rather than force. This is very civilized-and civilizing!" Anderson, Stanley V. (1983). "The Corrections Ombudsman in the United States". Int'l Handbook of the Ombudsman, 137, p. 143.

16 "[W] hen a public body fails to act in accordance with a rule or principle which is binding upon it" Cominelli, Luigi (2002). "An Ombudsman for the Europeans: Gradually Moving Towards "Effective Dispute Resolution" Between Citizens and Public Administrations". The International Ombudsman Yearbook, volume 6, pp. 143-182, p. 167.

17 Pliakos, Asteris (2002). The Ombudsman for supervision of the application of Community law. Citado por Cominelli, Luigi. (2002). 
punto de vista de Alarcón, bajo este modelo, un principio guía en una investigación del Ombudsman debe ser si la acción bajo investigación es ilegal, irracional, injusta, opresiva, impropiamente discriminatoria, fácticamente deficiente o de otra manera errónea ${ }^{18}$.

Junto a este modelo de Ombudsman nos encontramos con otro perfil de institución, definida, como se verá a continuación, por la defensa de los derechos humanos.

\section{El modelo iberoamericano: análisis comparado actual}

Se ha sostenido más arriba que en este trabajo se preferirá la denominación de Defensor del Pueblo para esta institución, ya que es la más común en castellano y además, la más común en la región de Iberoamérica. En efecto, en el continente americano, solo hay cuatro países que optan por la denominación de Procurador de Derechos Humanos o similar ${ }^{19}$. Hay dos países que optan por Comisión Nacional de Derechos Humanos $^{20}$. Pero hay nueve países que optan por utilizar la denominación de Defensor del Pueblo o similar ${ }^{21}$.

En el modelo iberoamericano, el Defensor del Pueblo se puede definir como una institución pública, creada ya sea por la Constitución o por la ley, y regulada por esta última, con estatuto autónomo, funcional y financieramente autónomo, que goza de independencia en el cumplimiento de sus funciones, y que tiene por misión primordial promover y proteger los derechos de los individuos, comunidades y pueblos, frente a actos provenientes del Estado o de terceros, que amenacen, perturben o priven de sus derechos a estos últimos.

A título de comparación podemos describir las facultades del Ombudsman clásico y aquellas del Ombudsman iberoamericano. En el caso del clásico se pueden listar las siguientes características: 1. Independencia; 2. Ausencia de poder de anulación; 3. Su presencia inhibe la mala administración; 4. Ausencia de formalidades; 5. Pretende la composición amistosa; 6. Impide cometer mismos errores ${ }^{22}$. Aun cuando con ligeras diferencias, las características del Ombudsman iberoamericano son las mismas que las del Ombudsman de origen escandinavo, a ello hay que agregarle la facultad de acción procesal y su finalidad cual es claramente

18 Alarcón, Arthur L. (2007). 598.

19 Guatemala (1985), El Salvador (1991), Nicaragua (1995, con la denominación de Procurador para la Defensa de los Derechos Humanos) y Puerto Rico (con la denominación de Procurador del Ciudadano).

21 Colombia (1991), Paraguay (1992), Argentina (1993), Perú (1993), Bolivia (1994), Ecuador (1996), Panamá (1996), Venezuela y Costa Rica (1992, con denominación Defensor de los Habitantes).

Islas Colin, Alfredo e Islas Colin, Marco Antonio (2007). 180. 
la defensa y protección de los derechos humanos. En este sentido, Aguiar de Luque ha dicho que esta última característica es el rasgo distintivo del Defensor del Pueblo español. En efecto, algo que lo identifica es "su focalización en la defensa de los derechos fundamentales (sic) lo que explica alguna de sus facultades, como la de hallarse facultado para interponer recursos de inconstitucionalidad que carecería de sentido desde su estricta consideración como comisionado de las Cortes"23. Por otra parte, en el caso del Defensor del Pueblo argentino, Maiorano ha señalado que este responde a las siguientes premisas: a) es una institución constitucional; b) su misión es doble, por un lado, la tutela de los derechos humanos de todos y, por otro, el control del ejercicio de las funciones administrativas públicas; c) el objeto de su control son los hechos, actos y omisiones; d) "en particular, su función de garantía ha sido prevista por los convencionales constituyentes para defender los derechos que protegen al ambiente, a la competencia, a los usuarios y consumidores y los derechos de incidencia colectiva"; e) carece de coacción jurídica tradicional; f) no modifica, crea o extingue relaciones jurídicas puesto que actúa en el ámbito de la persuasión; g) en sus facultades de investigación puede operar el delito de desobediencia; y h) legitimado para demandar al Estado cuestionando actos, hechos $\mathrm{u}$ omisiones administrativas ${ }^{24}$.

Según Mugica, es perfectamente posible hacer una tipología de Ombudsman y destacar, quizás bajo la forma del Defensor del Pueblo, el modelo iberoamericano de Ombudsman o Defensor del Pueblo, "cuyas características han seguido, a grandes rasgos, la huella de los defensores en Espańa y Portugal" 25 . En palabras similares Monti ha precisado que el Defensor del Pueblo, "[e]n América Latina, se propaga a partir de la década de 1990 siguiendo el modelo español y con un perfil de primordial defensa de los derechos humanos" 26 .

En Latinoamérica, el Ombudsman o Defensor del Pueblo es incorporado por primera vez en la Constitución de Guatemala en el año 1985, bajo la modalidad de Comisionado del Congreso de la República y con el nombre de Procurador de los Derechos Humanos, y de ahí en adelante esta institución comenzará a extenderse a otros países del continente. En este sentido, Islas Colín seńala que "el ombudsman latinoamericano nació a principios de los ańos noventa, se especializó en la protección no juris-

Aguiar De Luque, Luis (2001): "Defensor del Pueblo". En Aragón Reyes, Manuel (Coord.). Temas básicos de Derecho Constitucional, Tomo III. Civitas, Madrid: p. 229.

24 Matorano, Jorge Luis (1998). "El Defensor del Pueblo de la Nación: su función tutelar en el ámbito de la regulación económica". Revista Jurídica de Buenos Aires, vol. III, pp. 69-70, p. 71.

25 Mugica Herzog, Enrique (2006) Defensor del Pueblo: el modelo iberoamericano. Conferencia del Defensor del Pueblo, Excmo. Sr. Don Enrique Mugica Herzog, en la XIX edición del curso Postgrado en Derecho Constitucional, Universidad de Salamanca, Salamanca, p. 2. Monti, Eduardo Jorge. 40. 
diccional de los derechos humanos, se creó poco a poco en América Latina, sin olvidar su origen nórdico y europeo" 27 . Desde el punto de vista de esta primera experiencia, la Constitución de Guatemala señala en su artículo 274 que "El procurador de los Derechos Humanos es un comisionado del Congreso de la República para la defensa de los Derechos $\mathrm{Hu}$ manos que la Constitución garantiza. Tendrá facultades de supervisar la administración; ejercerá su cargo por un período de cinco años, y rendirá informe anual al pleno del Congreso, con el que se relacionará a través de la Comisión de Derechos Humanos". Además, el artículo 275 f) de la Constitución de Guatemala señala como atribución del Procurador la de "promover acciones o recursos, judiciales o administrativos, en los casos en que sea procedente". Como se ha reiterado, al incorporarse el Defensor del Pueblo a los ordenamientos jurídicos del continente americano, "se ha encontrado con múltiples tareas y retos que van más allá de su función mediadora entre la administración pública y el ciudadano"28. Efectivamente, los rasgos distintivos del Defensor del Pueblo iberoamericano son legitimación procesal y defensa de los derechos humanos, aspectos que - para cumplir con los Principios de París- deberían estar fuertemente presentes en el proyecto chileno.

La figura del Defensor del Pueblo se entiende y justifica plenamente, cada vez con mayor necesidad, en el contexto del constitucionalismo del siglo XXI, el constitucionalismo de la libertad, de la democracia, de la solidaridad y de la supremacía de los derechos humanos ${ }^{29}$. En efecto, este es un constitucionalismo que reconoce las libertades de los individuos, y, por tanto, que restringe y controla las atribuciones de los poderes públicos, particularmente de la Administración del Estado, con la que el individuo, los grupos y pueblos interactúan cotidianamente. Pero además, un constitucionalismo que reconoce el principio de la igual dignidad humana y, al mismo tiempo, de la desigualdad fáctica entre los individuos, grupos y pueblos. Una constatación empírica real del constitucionalismo contemporáneo es la existencia de vulnerables, de los débiles, abandonados o despojados, tales como niños, indígenas, trabajadores, encarcelados, etc. ${ }^{30}$ En este sentido, el constitucionalismo del siglo XXI es eminentemente social y solidario, que tiene como corolario el principio y valor constitucional del bien común. En otras palabras, y tal como lo ha dicho el Tribunal Constitucional peruano, el constitucionalismo contemporáneo es el de un

Islas Colin, Alfredo e Islas Colin, Marco Antonio (2007). 180.

Briceño Vivas, Gustavo (1995). Un Ombudsman para la democracia, $1^{a}$ edición. Medellín: Editorial Biblioteca Jurídica Dike, p. 7.

MonTI, Eduardo Jorge. 32.

A propósito de los recluidos y privados de libertad y de las condiciones carcelarias, obsérvese el artículo 129.2. de la Constitución boliviana que dice "El Defensor del Pueblo, para ejercer sus funciones, tiene acceso libre a los centros de detención, reclusión e internación". 
Estado social y democrático de derecho que consiste en un Estado "que sin desconocer los intereses individuales, los integra a los intereses de la sociedad, bajo el entendido que la realización de los primeros no puede darse sin el concurso de los segundos" 31 . En virtud de este principio de la solidaridad, el constitucionalismo contemporáneo ha fijado la justicia social, en el eje central de sus logros. En este contexto, pues, el Defensor del Pueblo forma parte de las estructuras constitucionales necesarias y puede ser un instrumento preciso para concretar en los individuos y grupos al interior del Estado el principio de solidaridad, justicia social y bien común. Así, Maiorano señala precisamente que la formulación del Defensor del Pueblo "emana directamente de necesidades sociales recientes, provocadas por tecnologías avanzadas y mercados ampliados" 32 . Como dice Parejo Alfonso, el Defensor del Pueblo está inspirado en los valores colectivos del orden constitucional ${ }^{33}$. Y, como se ha dicho, el valor supremo del orden constitucional es el bien común. Por esta razón, cabe tener en cuenta que "si las grandes mayorías ven resignar sus legítimos beneficios sociales por la tolerancia del poder administrador o por la codicia del poder económico, será difícil que la justicia social sea el patrimonio moral de la República" 34 . En consecuencia, en un Estado social y democrático de derecho, "los derechos del individuo no son excluyentes de los intereses de la sociedad, pues la realización de uno no puede ser sin el concurso del otro" 35 . Esta solidaridad ineluctable entre los individuos y grupos, es lo que Kelsen llama el principio de la democracia social en donde, según Kelsen "para que pueda originarse la noción de una forma social democrática, la idea de igualdad ha de agregarse a la de libertad, limitándola" 36 .

En la versión contemporánea, ibérica y latinoamericana, de esta Institución, el Defensor del Pueblo es un defensor de los derechos humanos de todos, individuos, grupos y pueblos, y particularmente, de acuerdo con el espíritu central de los derechos humanos, de los vulnerables, de aquellos más desvalidos, débiles o despojados. En este sentido no se visualiza, tal como indica Suárez, una razón para limitar los órganos o agentes a ser controlados por el Defensor. En efecto, este profesor ha señalado que considera "un error reducir la actuación de la Defensoría a los actos u omisiones lesivos de derechos e intereses cometidos por órganos de la Administración pública e instituciones o personas prestadoras de servicios

Tribunal Constitucional Peruano, caso Ley 28.258-Ley de Regalias Mineras, Rol N. ${ }^{\circ} 0048$ 2004-AI/TC, de fecha 1 de abril de 2005, Fundamentos Jurídicos 1-10.

32 Maiorano, Jorge Luis (1998). 73.

33 Parejo Alfonso, Luciano (1992): "El Defensor del Pueblo como institución de control de la Administración Pública”. En VV.AA.: Diez años de la Ley Orgánica del Defensor del Pueblo. Problemas y Perspectivas, Madrid: Universidad Carlos III, pp. 103-132, p. 130.

34 Maiorano, Jorge Luis (1998). 79.

35 Tribunal Constitucional Peruano, Rol N. ${ }^{\circ} 0048-2004-A I / T C$, Fundamento Jurídico 4.

36 KeLSEN, Hans (1977) Esencia y valor de la democracia. 2a edición. Madrid: Labor, p. 138. 
de utilidad pública, excluyendo de una manera tan amplia a las Fuerzas Armadas y de Orden y Seguridad Públicas. Del mismo modo podría contemplarse sin temor que su actividad bienhechora se pudiera desplegar, incluso, sobre la propia Contraloría General de la República y sobre el Poder Legislativo. En lo que respecta al Poder Judicial, es cierto que no todos los países acogen la supervisión del Ombudsman sobre el Poder Judicial, principalmente porque se ha observado que ello puede atentar contra su independencia. Sin embargo, hay actuaciones administrativas de los tribunales que dada la inexistencia de un Consejo Nacional de la Magistratura pudieran ser controladas por la Defensoría. [...]. Se justifica también que el Defensor pueda actuar ante situaciones evidentes de dilaciones indebidas o de violación de los principios básicos del debido proceso. No se observa la razón por la cual los ciudadanos deban quedar ajenos a la protección del Ombudsman en un aspecto tan importante. Lo mismo puede decirse del Poder Legislativo, frente al cual se consulte la actividad del Defensor en la prevención de decisiones legislativas que eventualmente afecten derechos fundamentales" 37 . En este orden de ideas, por ejemplo, la Ley Orgánica del Defensor del Pueblo en Venezuela, deja claro que la actividad de control del Defensor abarca todos los órganos del Estado, cuando señala que "[1] a actividad de la Defensoría del Pueblo abarca las actuaciones de cualquier órgano y funcionario perteneciente al Poder Público Nacional, Estadal o Municipal, en sus ramas Ejecutiva, Legislativa, Judicial, Electoral y demás órganos del Poder Ciudadano, incluso en el ámbito militar. Abarca igualmente la actuación de particulares que presten servicios públicos o cualquier otra actividad de conformidad con la Constitución y las leyes" 38 . En definitiva, lo que se pretende a través de la actuación del Defensor es que el Estado cumpla su cometido constitucional de protección y respeto de los derechos humanos y no se convierta -en el mundo contemporáneo- en un Estado de papel ${ }^{39}$.

\section{EL ROL DEL DEFENSOR DEL PUEBLO EN LA PROMOCIÓN Y PROTEC- CIÓN DE LOS DERECHOS HUMANOS}

Resulta de particular relevancia establecer primeramente que la institución del Defensor del Pueblo es una institución nacional de derechos humanos y que, en consecuencia, se debería sujetar a los denominados Principios de París. En este sentido, el Defensor del Pueblo se coloca jun-

Suárez Crothers, Christian (2001). “'Tiene alguna justificación la introducción del Ombudsman en el ordenamiento jurídico chileno?". Revista Ius et Praxis, núm. 1, pp. 559-574, especialmente, p. 572. 
to a instituciones como las Comisiones Nacionales de Derechos Humanos, los Institutos Nacionales de Derechos Humanos, los Procuradores de Derechos Humanos, los Abogados Públicos o Abogados del Pueblo, etc.

Desde el punto de vista del Derecho Internacional Público, la Asamblea General de la Organización de las Naciones Unidas aprobó mediante su resolución 48/134, de 20 de diciembre de 1993, los Principios relativos al estatuto de las instituciones nacionales de promoción y protección de los derechos humanos, conocidos como los Principios de París. Estos Principios contienen los criterios básicos a los cuales debería someterse toda institución nacional eficaz de defensa de los derechos humanos, son elementales, en el sentido de criterios mínimos lo que significa que si no se cumplen o no están presentes, no se podría garantizar que la institución nacional de promoción y protección de los derechos humanos funcionaría adecuadamente para el fin para el cual fue creado. Desde esta perspectiva, la figura del Defensor del Pueblo y su institucionalidad estatutaria debe someterse absolutamente a los Principios de París, para estar conforme a los estándares internacionales acordados ${ }^{40}$.

Desde esta perspectiva, los seis criterios básicos contenidos en los Principios de París son: i) independencia garantizada por texto constitucional o legislativo, ii) autonomía respecto al gobierno, iii) pluralismo, incluida su composición, iv) mandato amplio, basado en las normas universales de derechos humanos, v) facultades de investigación adecuadas y vi) recursos adecuados.

Del mismo modo, países que han avanzado más, proporcionando una mayor protección de sus derechos humanos a los individuos, comunidades y pueblos, no solo han creado la figura del Defensor del Pueblo, con esta $\mathrm{u}$ otras denominaciones, sino también han diversificado la institución especificando los destinatarios de su protección, tales como el Defensor de los Nińos u Ombudsman para los Nińos ${ }^{41}$, el Defensor de

El Comité Internacional de Coordinación de las Instituciones Nacionales de Promoción y Protección de los Derechos Humanos (CIC) es un órgano representativo de las instituciones nacionales de derechos humanos establecido con el fin de crear y reforzar instituciones nacionales de derechos humanos que sean conformes a los Principios de París. Su labor es la de crear y reforzar instituciones nacionales y garantizar que se ajusten a los Principios de París. El Comité Internacional de Coordinación otorga estatuto consultivo a las instituciones nacionales de derechos humanos según el cumplimiento de los Principios de París, ver también en www.ohchr.org/EN/Countries/NHRI/Pages/NHRIMain.aspx y www.demotemp360.nic. in/default.asp (sitio Internet de National Human Rights Institution Forum)

41 Esta figura existe principalmente en Europa, por ejemplo, se puede mencionar la existencia del Défenseur des Enfants (Francia); National Council for Children (Dinamarca) y el Ombudsman for Children (Irlanda). En 1997, se estableció una Red Europea de Ombudsman para Nińos que se llama ENOC (European Network for Ombudsman for Children). Su sitio Internet es: www.ombudsnet.org/ENOC. En Lima, Perú, en noviembre del 2007, se creó una Red Iberoamericana de Defensa de los Derechos de la Niñez y Adolescencia, con 11 defensores del pueblo centroamericanos y sudamericanos. Más información en www. crin.org/resources/infodetail.asp?id=15688 Sobre este tema: UNICEF Innocenti Research 
los Trabajadores, el Defensor de los Consumidores, etc. ${ }^{42}$ El Defensor del Pueblo es, sin duda, una institución necesaria en una sociedad democráti$\mathrm{ca}$, porque permite asegurar, como se verá a continuación, un mayor acceso a la justicia a los individuos y grupos vulnerables.

\section{Acceso a la justicia ${ }^{43}$}

Una de las materias más importantes que deben ser consideradas en las atribuciones del Defensor del Pueblo se encuentra el amplio rango de su control, que debe incluir no solo los abusos provenientes del Estado, considerado como administración del Estado, sino abusos provenientes de cualquier rama del Estado, Ejecutivo, Legislativo y Judicial. En este control de las actuaciones de las diversas unidades administrativas del Estado no puede ni debe existir limitaciones, porque ese solo hecho ya socavaría la figura, el objetivo y el fin para el cual fue creado el Defensor del Pueblo y en este sentido, el legislador, no puede defraudar los principios y fines constitucionales, sino que tiene la obligación de abstenerse de cualquier acto que frustre el objeto y fin del Defensor del Pueblo, el cual se desprende de los parámetros constitucionales e internacionales ${ }^{44}$. En esta línea se ha pronunciado Abramovich cuando ha señalado que "[d]e lo que se trata entonces es de reforzar el funcionamiento de los mecanismos internacionales como instancias de protección, pero a la vez influir en que los gobiernos cumplan con esos derechos y se fortalezcan los mecanismos de tutela de las personas dentro de los países, la aplicación de los tratados por los tribunales nacionales, la incorporación de la jurisprudencia del sistema en las decisiones de los tribunales constitucionales, y su utilización como principios que guíen las políticas públicas (por ejemplo, con la mediación de oficinas especializadas como las secretarías de derechos humanos y las defensorías del pueblo)" 45 . En el contexto del control estatal,

Centre (2001) Independent Institutions Protecting Children's Rights, Innocenti Digest, No 8; UNICEF Innocenti Research Centre (2006), The General Measures of the Convention on the Rights of the Child: The Process in Europe and Central Asia, pp.17-25.

Sobre el tema del Ombudsman de los nińos: Cisneros Farías, Germán (2007) "Reflexiones sobre el establecimiento del Ombudsman de los nińos. Concepto y tareas específicas". En Cisneros Farías, Germán; Fernández Ruiz, Jorge y López Olivera, Miguel Alejandro (Coord.). Ombudsman local. Segundo Congreso Iberoamericano de Derecho Administrativo. México: Instituto de Investigaciones Jurídicas, UNAM, pp. 143-149.

Sobre acceso a la justicia en general: Valladares, Leo (2000) El Ombudsman como canal de acceso a la justicia. Disponible en: www.juridicas.unam.mx/publica/librev/rev/iidh/cont/32/ pr/pr3.pdf; Cançado Trincade, Antonio A. (2008) El Derecho de acceso a la justicia en su amplia dimensión. Santiago de Chile: Editorial Librotecnia.

Fitzgerald, Oonagh E. (Ed.) (2006) The Globalized Rule of Law: Relationships Between International and Domestic Law. Toronto: Irwin Law, p. 499.

Aвramovich, Víctor (2006). "Una aproximación al enfoque de derechos en las estrategias y políticas de desarrollo". Revista de la CEPAL, núm. 88, p. 49. 
Bolívar señala que "el tema del Ombudsman se aborda en relación con el control eficaz, no solo en lo que hace relación con los casos que conoce, sino también sobre las situaciones temáticas. A esto nos referimos en el sentido de fortalecer su función no solamente en la situación casuística, sino también en los problemas estructurales, los problemas de fondo" 46 .

Pero además, el Defensor del Pueblo debería estar en condiciones de efectuar un control de los actos de los particulares cuando estos sean violatorios de los derechos humanos, especialmente, en situaciones de franca desigualdad o desventaja como aquella que ocurre en las relaciones de consumo o en las relaciones laborales ${ }^{47}$. Esta última idea se encuentra en perfecta concordancia con el principio básico, común al constitucionalismo e internacionalismo contemporáneo, consistente en el primado del derecho, es decir, el sometimiento absoluto tanto de gobernantes como de gobernados a la regla de derecho, lo que traduce una de las mayores y más exitosas conquistas de la humanidad en el sentido de aseverar que nadie se encuentra por sobre el Derecho. Este principio de primacía del Derecho -un verdadero éxito de la civilización- se ve ampliamente representado, inter alia, en el principio de acceso a la justicia.

Tal como ha señalado Méndez Pinedo, "el acceso a la justicia puede ser definido como el derecho humano más básico y fundamental de todo Estado Social de Derecho, ya que consiste en el ejercicio de las acciones procesales necesarias para la defensa de los derechos sustantivos. Los nuevos derechos adquiridos en la sociedad moderna pueden ser caracterizados como derechos sociales y plantean un problema fundamental a la hora de garantizar su eficacia, sobre todo si afectan a intereses generales o difusos" $" 48$.

La manera de entender el acceso a la justicia seńalada precedentemente, puede ser vista con una significación aun más amplia, si atendemos a lo que señala Claude en el sentido de que "el término acceso a la justicia sirve para denominar dos objetivos básicos del sistema legal dentro del cual los ciudadanos pueden ejercer sus derechos o resolver sus litigios bajo la tutela del Estado. En primer lugar el sistema debe ser accesible a

Bolívar, Ligia (2001). "Justicia y acceso. Los problemas y soluciones". Revista del IIDH, vol. 32-33, pp. 71-91, p. 88.

47 Para analizar una opinión contraria: Fitzgerald, Oonagh E. (Ed.) (2006) 514.

48 Méndez Pinedo, Elvira (1998) La protección de consumidores en la Unión Europea: hacia un derecho procesal comunitario de consumo. Madrid: Marcial Pons, pp. 145 y ss; Interesante resulta tener en cuenta lo que seńala Cruz Villalón en el sentido de que "de entre las diversas garantías a través de las cuales la Constitución protege la eficacia de los derechos fundamentales (normativas, institucionales, entre otras) cabe destacar la protección jurisdiccional, entendiendo por tal la encomendada a los jueces y tribunales a través de la función jurisdiccional atribuida a aquellos de forma exclusiva como parte del derecho a la tutela efectiva de los derechos e intereses legítimos". Cruz Villalón, Pedro (2001) "Protección jurisdiccional de los derechos fundamentales". En Aragón Reyes, Manuel (Coord.). Temas básicos de Derecho Constitucional, Tomo I. Madrid: Civitas, 2001, p. 226. 
todos; en segundo lugar, debe procurar resultados justos tanto individual como socialmente" 4 ?

En este contexto, el Defensor del Pueblo se erige en un veedor del cumplimiento de la regla de derecho en el orden de los derechos humanos, quien vela y persigue, incluso ante instancias judiciales, por el respeto y protección de los derechos humanos. Además, en este último sentido, el Defensor del Pueblo se constituye en un medio adicional eficaz para la satisfacción del principio de acceso a la justicia, ya que aumenta, amplia y complementa la posibilidad que tienen los individuos y grupos de ver realizados sus derechos humanos a través de la petición o respectivo recurso, ya sea administrativo o jurisdiccional. En este importante sentido, Monti ha señalado que "en este camino de acceso a la justicia adquiere protagonismo la figura del Ombudsman a quien ya no se le desconoce legitimación para obrar en representación de intereses individuales y colectivos" ${ }^{50}$. Por esta razón, la existencia misma del Defensor del Pueblo es una medida objetiva adoptada por el Estado que permite, además, avanzar en los niveles de intensidad y profundidad en el cumplimiento del principio de acceso a la justicia de la comunidad. Esto último se encuentra en total consonancia con el cumplimiento de uno de los Principios de París, consistente en que "[l]a institución nacional podrá estar facultada para recibir y examinar denuncias y demandas relativas a situaciones particulares. Podrán recurrir a ella los particulares, sus representantes, terceros, organizaciones no gubernamentales, asociaciones y sindicatos y cualquier otra organización representativa" ${ }^{51}$. Lo anterior adquiere particular relevancia en el caso de individuos o grupos especialmente vulnerables, tales como los pobres, los discapacitados, las mujeres, los niños, los indígenas, etc. La facultad que debiera tener el Defensor del Pueblo de iniciar procesos judiciales mediante el correspondiente ejercicio de la acción, vale decir, la atribución de poner en movimiento los tribunales interno e internacionales, en su caso, con el objeto de procurar la protección de los derechos humanos de todos, esto es, de individuos, comunidades y pueblos, no es sino la única manera de asegurar que los derechos consagrados en el sistema de protección de los derechos humanos sean una realidad palpable y no queden en el plano de la hipótesis, o en el nivel teórico o meramente ilusorio. En este sentido, Lorenzetti ha destacado que la legitimación procesal del Defensor del Pueblo facilita "el acceso a la justicia de una gran cantidad de personas mediante la representación de un organismo pú1993. Anexo, Principios relativos al estatuto de las instituciones nacionales. 
blico, lo que involucra (sic) las relaciones entre comunidad y proceso" 52 . En consecuencia, desde el punto de vista de lograr un acceso universal a la justicia, resulta fundamental el rol de representación de intereses que puede jugar el Defensor del Pueblo, para lo cual es imprescindible dotar a esta institución de legitimidad activa. Este último ha sido generalmente el modelo adoptado por los países latinoamericanos. Incluso, el CDN ha instado a que el Defensor asuma esta representación judicial del niño en su Observación General No 2, permitiendo expresamente la mediación o conciliación previa antes de una acción judicial ${ }^{53}$.

En efecto, el rol que le corresponde al Defensor del Pueblo en derechos humanos lo ejerce en el ámbito doméstico, ante los tribunales de justicia locales, como ante las instancias supranacionales de protección de los derechos humanos, cuando se desconozcan las obligaciones internacionales en derechos humanos. De este modo, la Defensoría del Pueblo puede operar como un activo promotor de la consolidación de una práctica institucional y generalizada, respetuosa de los derechos humanos. Incluso más, este es uno de los mandatos derivados de los Principios de París, cuando señala que las instituciones nacionales tendrán la facultad de "promover y asegurar que la legislación, los reglamentos y las prácticas nacionales se armonicen con los instrumentos internacionales de derechos humanos en los que el Estado sea parte, y que su aplicación sea efectiva" y "alentar la ratificación de esos instrumentos o la adhesión a ellos y asegurar su aplicación”. Además, los Principios de París consideran como atributo del INDH "contribuir a la elaboración de los informes que los Estados deban presentar a los órganos y comités de las Naciones Unidas, así como a las instituciones regionales, en cumplimiento de las obligaciones que les imponen los tratados y, en su caso, emitir una opinión a ese respecto, en el marco del respeto de su independencia" 54 .

Uno de los ejemplos, entre muchos, que se pueden proporcionar a propósito de la facultad de acción judicial por parte del Defensor del Pueblo, la encontramos en el caso español, de acuerdo con lo dispuesto en el artículo 162 de la constitución española y 32 y 46 de la Ley Orgánica del Tribunal Constitucional español, el cual ha servido de fuente de inspira-

LoRenzetti, Ricardo (2000) "Dańos masivos, acciones de clase y pretensiones de operatividad". En Jurisprudencia Argentina, 7 de junio de 2000.

53 "A continuación figura una lista indicativa, no exhaustiva, de los tipos de actividades que las instituciones nacionales de derechos humanos deberían llevar a cabo en relación con el ejercicio de los derechos del nińo a la luz de los principios generales enunciados en la Convención: $[\ldots]$ p) Iniciar procedimientos judiciales para reivindicar los derechos del niño en el Estado o brindar a los nińos asistencia jurídica; q) Entablar, cuando proceda, procesos de mediación o conciliación antes de que se recurra a una acción judicial;" CDN (2002) Observación General No 2, par. 19 p) y q).

54 Naciones Unidad (1993) Resolución de la Asamblea General 48/134 de 20 de diciembre, Anexo, Principios relativos al estatuto de las instituciones nacionales, par. 3. b), c) y d). 
ción para muchos países del continente americano. Esta constituye una de las particularidades más relevantes de la institución espańola y constituye una innovación de gran importancia dentro del marco tradicional de competencias del Ombudsman. Un caso concreto lo encontramos con ocasión del recurso de inconstitucionalidad que, con fecha de 22 de febrero de 2000, interpuso el Defensor del Pueblo espańol, contra diversos preceptos de la Ley Orgánica 15/ 99, de 13 de diciembre, sobre Protección de Datos de Carácter Personal, atendido a que "uno de los posibles medios de agresión a ese ámbito reservado de vida donde se desenvuelve el derecho a la intimidad o a la vida privada, puede ser el tratamiento automatizado de datos personales mediante técnicas informáticas" ${ }^{\prime 5}$. El Defensor del Pueblo es una institución que sin duda fortalece el principio de acceso a la justicia de todos los individuos, grupos y pueblos que se encuentren bajo su jurisdicción. En la misma línea, "la Constitución política colombiana faculta al Defensor del Pueblo a interponer las acciones de tutela, sin perjuicio del derecho que asiste a los interesados'”56.

Al final de su investigación, el Ombudsman puede recomendar que se adopten medidas de carácter correctivo, ya sea específicas, en un caso individual, o generales, a través de modificaciones legislativas o reformas a las políticas o procedimientos administrativos. Esta última es la razón por la cual se denomina al Defensor del Pueblo como un Magistrado de persuasión, lo que quiere decir que, prima facie, el Defensor obtiene resultados por sus razones no por poseer potestad coercitiva. En definitiva, el Defensor efectúa recomendaciones a las administraciones públicas u órganos o personas controladas, no da órdenes porque carece de facultades coercitivas. En definitiva, en caso de órgano, agente o persona recalcitrante, el Defensor debe dar cuenta al Parlamento, ya sea en un informe particular o en su cuenta pública. "El informe se hará de conocimiento público. Este es sin duda la principal arma con que cuenta el Ombudsman para asegurar el cumplimiento de sus recomendaciones: la posibilidad de darlas a conocer a la opinión pública" 57 .

En Canadá, por ejemplo se ha insistido en que, tratándose del $\mathrm{Om}$ budsman for Children, se respeten completamente los Principios de París, en particular que ejerzan sus funciones con absoluta independencia ${ }^{58}$. De hecho, los requerimientos mínimos exigidos para que un Defensor del

Аваd Amoros, Ma Rosa (2000). "El Recurso de Inconstitucionalidad del Defensor del Pueblo contra la LO 15/99 de Protección de Datos de Carácter Personal". REDI Revista Electrónica de Derecho Informático, Núm. 28, pp. 1-14, p. 3. comparada. México: Universidad Nacional Autónoma de México, p. 85; Artículo 282, numeral 3a, Constitución Política de Colombia.

58 Fitzgerald, Oonagh E. (Ed.) (2006): The Globalized Rule of Law: Relationships Between International and Domestic Law. Toronto: Irwin Law, p. 499. 
Pueblo pueda ejercer sus funciones y cumplir con sus fines es que en su establecimiento se debe cumplir con los Principios de París, tener poderes investigadores, cubrir toda la administración del Estado, y recibir un mandato expreso para aplicar todo el Derecho Internacional de los derechos humanos y el Derecho Constitucional de los Derechos Humanos ${ }^{59}$. En efecto, el Defensor del Pueblo debe tener una aproximación comprensiva, expansiva e integrada de los derechos humanos cuya promoción y protección le corresponde efectuar. Esto último significa que en su labor de control y protección el Defensor del Pueblo debe nutrirse tanto de los principios y normas constitucionales como de los estándares y normas internacionales en materia de derechos humanos.

En este orden de ideas, el Defensor del Pueblo puede jugar un valioso rol en el desarrollo, al nivel doméstico, de los derechos humanos, aplicando obligaciones internacionales emanadas de tratados de derechos humanos que no hayan sido implementados expresamente en el ámbito doméstico o de la costumbre internacional o incluso usar soft law internacional para interpretar el derecho interno o dar significado a los estándares más amplios del Ombudsman de justicia usados para escrutar la conducta administrativa ${ }^{60}$. Esta aproximación a los estándares de los derechos humanos por parte del Defensor del Pueblo debería ser utilizada en todas y cada una de sus actividades, ya sean de promoción, educación o procesamiento de quejas ${ }^{61}$. En general, en Canadá, los Ombudsman provinciales han recurrido al Derecho Internacional de los derechos humanos, incluso al Derecho Internacional de los derechos humanos in status nascendi, para determinar sus estándares más amplios de equidad y justicia, los estándares de acuerdo a los cuales va a efectuar su control ${ }^{62}$.

Uno de los defectos que se han detectado para el adecuado desarrollo de las actividades del Defensor del Pueblo es la falta de recursos humanos y financieros así como la escasa autonomía financiera en la administración de los mismos. Por ejemplo, en el caso colombiano, se ha señalado que "la Defensoría goza de personería jurídica y de patrimonio propio; sin embargo, su presupuesto de funcionamiento debe ser sometido a consideración del gobierno nacional y no es aprobado directamente por el Congreso de la República, lo que se ha traducido en una dependencia financiera respecto del poder ejecutivo" 63 . Evidentemente, la escasez de recursos implica un atentado directo al correcto, autónomo y eficaz desempeño de las 
funciones propias del Defensor del Pueblo como ha sido el caso de varias de las instituciones nacionales de derechos humanos en Canadá64.

En este sentido, se ha pronunciado el Comité para la Eliminación de la Discriminación Racial (en adelante CERD) cuando ha indicado, a propósito de las Conclusiones Finales para Bosnia y Herzegovina, que "[e]l Comité recibe preocupado la noticia de que los fondos asignados al Ombudsman de los Derechos Humanos de Bosnia y Herzegovina son insuficientes y que este carece de autonomía financiera. También preocupa al Comité saber que la eficacia y la eficiencia de esta institución se ven reducidas a causa de su estructura tripartita. El Comité recomienda al Estado Parte que garantice la autonomía financiera y la eficacia funcional de la Oficina del Ombudsman, de conformidad con los Principios de París de 1993, y que, de producirse una fusión entre las Oficinas del Ombudsman del Estado y las de sus entidades constitutivas, esta se lleve a cabo con el objetivo de garantizar que la defensa de los derechos humanos se realice desde una perspectiva global y no dividida por etnias" 65 .

En el caso canadiense, las diversas oficinas de Ombudsman, las oficinas provinciales, imparcialmente investigan conductas relacionadas con la administración pública por motivos de ilegalidad, discriminación impropia, varios criterios de procedimientos injustos y otros estándares de conductas ilícitas o injustas. El Ombudsman en general formula recomendaciones de cambio, informa a la legislatura en específicos casos si no se adoptan medidas por la administración, e informa a la legislatura en informes anuales y especiales ${ }^{66}$.

Finalmente, desde la perspectiva del derecho nacional, la Corte Constitucional de Colombia ha reforzado la aplicación de este principio elemental de protección de los derechos humanos, en su sentencia de 11 de mayo de 1992. En efecto, en dicha sentencia, la Corte colombiana señaló que la protección judicial "puede ser reclamada, en casos concretos, mediante el uso del mecanismo de la acción de tutela, concebida precisamente como medio idóneo para asegurar que los derechos trascienden del plano de la ilusión al de la realidad"67.

Uno de los requisitos básicos del ejercicio de cargos o empleos públicos es la necesaria apertura de los mismos desde el punto de vista de la posibilidad de acceso. En efecto, el derecho a los cargos o funciones públicas merece protección por parte del ordenamiento jurídico no solo por sí mismo sino "como medio encaminado a lograr la efectividad de otro

Fitzgerald, Oonagh E. (Ed.) (2006) 499.

CERD (2006) Observaciones finales del Comité para la Eliminación de la Discriminación Racial: Bosnia y Herzegovina. Doc. CERD/C/BIH/CO/6, de fecha 11 de abril, par. 9

67 Corte Constitucional de Colombia Sala Tercera de Revisión. Sentencia T-003 del 11 de mayo de 1992. 
derecho -genérico- cual es el de participar en la conformación, ejercicio y control del poder político, a objeto de realizar la vigencia material de la democracia participativa"68. Este es el caso del Defensor del Pueblo, aun cuando de esta apertura en el ejercicio del derecho no se pude colegir la falta absoluta de requisitos para optar a los cargos o funciones públicas, al menos, las más relevantes. En este sentido, la Corte Constitucional de Colombia ha seńalado que "el buen éxito de la gestión estatal y, por ende, el bien común, dependen de una adecuada preparación y de la idoneidad profesional, moral y técnica de las personas a las que se confía la delicada responsabilidad de alcanzar las metas señaladas por la Constitución"69. Por ejemplo, el caso de los requisitos para ser Defensor del Pueblo cuya misión es alcanzar el bien común por la vía de la promoción y protección de los derechos humanos. Evidentemente, en el caso de la Constitución chilena, una de las metas más importantes trazadas por la Constitución es la defensa de la dignidad humana y, por tanto, la promoción y protección de los derechos humanos.

Por otro lado, sin lugar a dudas, la tendencia progresiva que debiera seguirse es hacia la expansión y desarrollo tanto geográfico como temático del Defensor del Pueblo a fin de garantizar su plena accesibilidad. Esto significa que el Defensor debiera estar presente con oficinas y delegados $o$ adjuntos en todo el territorio nacional -en las distintas divisiones territoriales- (qué dice la Constitución sobre la división territorial de Chile) y generar secciones al interior de la institución especializadas, por ejemplo, Defensor del Nińo, Defensor del Consumidor, Defensor en las Quiebras, Defensor de los Indígenas, Defensor de las minorías, Defensor de los Trabajadores, Defensor del Contribuyente, etc. Defensores todos estos cuya actuación debiera estar inspirada en el Derecho Constitucional e Internacional de los derechos humanos. La peculiaridad de Defensor del Consumidor, Defensor del Trabajador y Defensor en las Quiebras es que en estos casos el defensor intervendría o tendría la oportunidad de intervenir en relaciones entre privados, situaciones en las cuales, como se sabe, también pueden verse vulnerados los derechos de los individuos y grupos. El CDN también se ha pronunciado sobre esta facultad de promoción y protección de los derechos humanos ya sea, en relación con los órganos de la Administración, como con entidades públicas y privadas ${ }^{70}$. La otra

\footnotetext{
68 Corte Constitucional de Colombia, Sentencia No C-487/93, de 28 de Octubre 1993, Considerando IV, p. 8.

69 Corte Constitucional de Colombia, Sentencia No C-487/93, de 28 de Octubre 1993, Considerando IV, p. 8.

70 "Se deben conferir a las instituciones nacionales las facultades necesarias para que puedan desempeñar su mandato con eficacia, en particular la facultad de oír a toda persona y obtener cualquier información y documento necesario para valorar las situaciones que sean de su competencia. Tales facultades han de comprender la promoción y protección de los derechos de todos los nińos que estén bajo la jurisdicción del Estado Parte en relación no solo con el
} 
posibilidad, es la creación constitucional separada de Instituciones paralelas y coordinadas con el Defensor del Pueblo.

Una activa interacción entre las instituciones independientes de derechos humanos y los órganos internacionales encargados de la promoción y protección de los derechos humanos presenta muchas ventajas recíprocas, entre ellas, un mejor entendimiento y uso de los instrumentos internacionales y regionales de derechos humanos, tal como se desarrollará a continuación.

\section{Interacciones: complementariedad y tensiones con los mecanis- mos nacionales, regionales e internacionales de promoción y pro- tección de derechos humanos}

Es un lugar común afirmar que la responsabilidad primordial en la difusión, el cumplimiento y la satisfacción de los derechos humanos, le corresponde al Estado. En efecto, bajo la óptica del constitucionalismo contemporáneo y desde la perspectiva del Derecho Internacional Público, el Estado tiene la responsabilidad primera en el cumplimiento de la obligación de promoción y protección de los derechos humanos. Los organismos internacionales, en especial, los órganos jurisdiccionales o casi jurisdiccionales internacionales solo cumplen un rol complementario y subsidiario respecto de aquel del Estado, tal como lo evidencia la regla del agotamiento previo de los recursos internos ${ }^{71}$.

Lo anterior es, a su vez, una manifestación de una interesante dualidad que le plantea el sistema de derechos humanos a los Estados. Por un lado, respeta el concepto subsistente de la soberanía del Estado en el sentido de ejercicio de funciones competenciales, como por ejemplo, la función jurisdiccional de promoción y protección de los derechos humanos. Por otra parte, manifiesta la definitiva mutación del concepto de soberanía estatal exclusiva y excluyente y lo desliga absolutamente de su idea clásica de la suma potestas y la plenitudo potestatis. Así, los derechos humanos han marcado la transformación de la soberanía estatal en un concepto poroso y permeable el cual está condicionado inexorablemente por las exigencias derivadas de los derechos humanos ${ }^{72}$. Estas exigencias derivadas de los derechos humanos van en un aumento ascendente, lo cual, a su vez, es una característica elemental de los derechos humanos mismos, estos es, su evolución expansiva irreversible. En este sentido, los desarrollos experimentados por el Derecho de los Derechos Humanos

Estado sino también con todas las entidades públicas y privadas pertinentes". CDN (2002) Observación General No 2, par. 9. 
en los últimos decenios, especialmente, en todo lo que tiene que ver con las obligaciones -tanto constitucionales como internacionales- en materia de derechos humanos en el ámbito de la equidad, los compromisos de desarrollo social, los derechos colectivos y la protección del medio ambiente han hecho necesario la ampliación y la adecuación del Estado mediante la adopción de medidas tendientes a satisfacer estas nuevas obligaciones. Del mismo modo, estos compromisos han exigido el desarrollo de la institucionalidad. En este contexto, se justifica la aparición de la figura del Defensor del Pueblo, como una figura más, adicional al aparato administrativo estatal, que tiene como finalidad primordial procurar la promoción y la protección de los derechos humanos, tanto individuales como colectivos, de todos los que se encuentren en el territorio del Estado.

El Defensor del Pueblo, como señala Parejo Alfonso, tiene la virtualidad de presentarse como una institución dinámica y flexible. En efecto, este autor pone de relieve este mecanismo "de acción independiente, pero inspirado en el orden constitucional y, por tanto, en los valores colectivos que este expresa y, al mismo tiempo, en términos de colaboración institucional y no en confrontación con la Administración Pública"73. No hay que verlo tan solo como un controlador y/o litigador, sino que hay que tener presente su gran potencial como un mediador o amigable componedor. Por ejemplo, en el caso colombiano "actúa también el Defensor del Pueblo a solicitud de las organizaciones cívicas o populares como mediador de las peticiones colectivas formuladas por estas frente a la administración pública" ${ }^{74}$. Desde esta perspectiva, los derechos humanos de los individuos y grupos que se vieran amenazados o incluso violados por la Administración o los servicios públicos o por quienes ejerzan actividades que satisfagan necesidades públicas, o incluso, finalmente, por privados, se verían respetados y su protección se alcanzaría por la vía de la colaboración más que por la vía de la confrontación. Esto último coadyuvaría a disminuir el elevado número de litigios - lo cual sería una importante contribución de esta institución a la vida social y democrática- y, por otro lado, no haría sino responder al amplio poder moral de que debería gozar el Defensor del Pueblo. En efecto, este no convence por la fuerza de sus decisiones sino, por la fuerza de sus argumentos. Esto hace que la doctrina lo califique de magistratura de opinión o de persuasión, justamente porque carece de imperio pero posee, sin duda, auctoritas ${ }^{75}$. El CDN ha resaltado, por su parte, una nueva modalidad de actuación del Defensor ante la jurisdicción, tanto nacional como internacional, esto es, intervenir 
ante el tribunal con sus conocimientos especializados, en calidad de amicus curiae ${ }^{76}$.

A partir de esta evidente importancia que ocupa el Defensor del Pueblo en el constitucionalismo democrático contemporáneo, se proyectan los beneficios que podrían surgir para los individuos y grupos, derivados de las distintas interacciones e interdependencias que aparecen o podrían producirse, tanto interna como internacionalmente, desde y hacia el Defensor del Pueblo. ¿Qué interacciones?

Por un lado, interrelación con los medios de comunicación social -que no son sus competidores- con el objeto de llegar a la opinión públi$\mathrm{ca}$, informarla y generar una opinión pública informada, consciente y capacitada para presionara a los actores políticos y sociales a fin de obtener la enmienda o corrección de los comportamientos.

Por otro lado, interrelación con las organizaciones intergubernamentales internacionales, especialmente, aquellas preocupadas de los derechos humanos, de individuos, grupos y pueblos. Desde luego, un Defensor del Pueblo o de las Personas del continente americano debiera mantener contacto y tener fluidas relaciones con la Organización de Estados Americanos (en adelante la OEA) y, particularmente, con los órganos del sistema interamericano de protección de los derechos humanos, a saber, la Comisión Interamericana de Derechos Humanos y la Corte Interamericana de Derechos Humanos.

Además, el Defensor del Pueblo debiera sostener fluidas relaciones de intercambio, cooperación técnica, investigación y denuncia con otros órganos de derechos humanos trascendentales, como son los órganos de vigilancia de los tratados de derechos humanos ${ }^{77}$. Estas convenciones internacionales, que poseen un órgano de supervisión o supervigilancia, se les conocen con el nombre de "fundamentales". En la actualidad, estos órganos son el Comité de Derechos Humanos, el Comité de Derechos Económicos; Sociales y Culturales, el Comité para la Eliminación de la Discriminación Racial, el Comité para la Eliminación de la Discriminación contra la Mujer, el Comité contra la Tortura, el Comité de los Derechos del Niño y el Comité para la protección de los Derechos de Todos los Trabajadores Migratorios y de sus Familiares ${ }^{78}$. Cabe hacer presente aquí que se han aprobado dos Convenciones de derechos humanos más, de las denominadas fundamentales. Nos referimos a la Convención Internacional para la protección de todas las personas contra las desapariciones forzadas y a la Convención sobre los derechos de las personas con discapacidad. La pri-

CDN (2002) Observación General No 2, par. 19.

Más información en: http://www.ohchr.org/EN/HRBodies/Pages/HumanRightsBodies.aspx Oficina del Alto Comisionado para los Derechos Humanos (2007) Folleto Informativo No.30, El Sistema de Tratados de Derechos humanos de las Naciones Unidas, Ginebra, Suiza, http://www.ohchr.org/Documents/Publications/FactSheet30sp.pdf 
mera Convención fue adoptada por la Asamblea General de las Naciones Unidas, por consenso, el 20 de diciembre de $2006^{79}$. Anteriormente, el Consejo de Derechos Humanos, mediante Resolución 1/1, de 29 de junio de 2006, había aprobado la Convención Internacional para la protección de todas las personas contra las desapariciones forzadas ${ }^{80}$. Esta Convención, a través de su artículo 26, crea un Comité contra la Desaparición Forza$\mathrm{da}^{81}$. La segunda Convención, fue adoptada por la Asamblea General de las Naciones Unidas, el 13 de diciembre de $2006^{82}$. Esta Convención, en su artículo 34, establece un Comité sobre los Derechos de las Personas con Discapacidad ${ }^{83}$.

¿Para qué y cómo esta interacción e interrelación con los órganos internacionales de vigilancia de los tratados?

La interacción entre el Defensor y los órganos de tratados puede ser, al menos, desde dos puntos de vista. Por un lado, en la etapa de elaboración y presentación del informe periódico por un Estado parte, la actuación del defensor puede ser de vital importancia para proporcionar al Comité de la información necesaria o complementaria o incluso, de un informe alternativo, al informe que periódicamente el Estado debe entregar al Comité seńalando el grado de cumplimiento de las normas del tratado respectivo. Así, por ejemplo, la Defensoría de los Habitantes de Costa Rica presentó al Comité de los Derechos del Niño una serie de comentarios al informe oficial del Estado de Costa Rica sobre la aplicación del Protocolo Facultativo de la Convención sobre los Derechos del Niño

79 La Asamblea General de las Naciones Unidas aprobó la referida Convención con fecha 20 de diciembre de 2006, Resolución A/RES/61/177, de fecha 12 de enero de 2007. Esta Convención aún no ha entrado en vigor.

80 Documentos Oficiales de la Asamblea General, sexagésimo primer período de sesiones, Suplemento No 53 (A/61/53), primera parte, cap. II, secc. A

81 "1. Para la aplicación de las disposiciones de la presente Convención, se constituirá un Comité contra la Desaparición Forzada (denominado en lo sucesivo "el Comité") integrado por diez expertos de gran integridad moral, de reconocida competencia en materia de derechos humanos, independientes, que ejercerán sus funciones a título personal y actuarán con total imparcialidad. Los miembros del Comité serán elegidos por los Estados Partes teniendo en cuenta una distribución geográfica equitativa. Se tendrá en cuenta el interés que representa la participación en los trabajos del Comité de personas que tengan experiencia jurídica pertinente y de una representación equilibrada de los géneros".

82 La Asamblea General de las Naciones Unidas aprobó la referida Convención con fecha 13 de diciembre de 2006, Resolución A/RES/61/106, 24 de enero de 2007. Esta Convención aún no ha entrado en vigor.

83 "1. Se creará un Comité sobre los Derechos de las Personas con Discapacidad (en adelante, "el Comité") que desempeñará las funciones que se enuncian a continuación. 2. El Comité constará, en el momento en que entre en vigor la presente Convención, de 12 expertos. Cuando la Convención obtenga otras 60 ratificaciones o adhesiones, la composición del Comité se incrementará en seis miembros más, con lo que alcanzará un máximo de 18 miembros". 
relativo a la venta de nińos, la prostitución infantil y la utilización de nińos ${ }^{84}$.

Por otro lado, en la etapa de seguimiento e implementación de las recomendaciones efectuadas por el Comité respectivo contenidas en las Conclusiones Finales al Informe de cada país. En esta etapa el Defensor puede convertirse en un verdadero coórgano de supervisión de tratados de derechos humanos, pero en el nivel interno, ya que coadyuvaría en el orden doméstico a la ejecución de las recomendaciones formuladas por el Comité. Dos elementos contribuirían a esta tarea. Por una parte, su función natural, clásica, tradicional, de ser un órgano contralor de la actuación de la Administración del Estado, a propósito de lo cual podría supervigilar la implementación de las recomendaciones. Por otra parte, su deber, también clásico, tradicional, de rendir cuenta ante el Parlamento, instrumento a través del cual el Defensor puede seńalar el estado de la implementación de las recomendaciones y denunciar el incumplimiento total o parcial de las mismas, a fin de que el Parlamento ejerza su jurisdicción política y su rol de fiscalización de los actos del Gobierno. Ahora bien, si el incumplimiento total o parcial de las recomendaciones del Comité provienen de actos del propio Parlamento, como perfectamente puede suceder si se dictan leyes que son contrarias a los compromisos internacionales en derechos humanos asumidos por el Estado o no se derogan leyes o normas que están en contradicción con los compromisos internacionales del Estado en derechos humanos, en ese caso, el Defensor, en su cuenta pública, debe hacerlo público, indicárselo al Parlamento y seńalarle que ese tipo de actos hacen incurrir al Estado en responsabilidad internacional. Por eso, reiteramos una vez más, que el Defensor no es solo un protector de los derechos humanos reconocidos en la Constitución, sino también de aquellos que obligan al Estado por la vía del Derecho Internacional, lo cual encaja en la lógica de un corpus iuris autónomo, de doble fuente. En esta labor de seguimiento en la implementación de las recomendaciones del Comité respectivo, cuya inejecución debe ser denunciada, las organizaciones de la sociedad civil pueden resultar ser un fuerte y precioso aliado del Defensor del Pueblo.

Por otra parte, las interacciones e interrelaciones entre el Defensor del Pueblo con las organizaciones de la sociedad civil son también de gran relevancia. Estas interacciones se deberían desarrollar en todos los ámbitos, tanto nacional, regional como internacional. De ahí la importancia de ejecutar una plan coordinado de cooperación interinstitucional con reconocidas ONGs internacionales, tales como Human Rights Watch, Amnistía Internacional, Greenpeace, o bien regionales, tales como Human 
Rights America, Cejil, etc. Por supuesto, en el nivel nacional, el punto de partida es la existencia de una sociedad civil verdaderamente organizada. En el caso de Chile, se han ido dando pasos importantes en este sentido, aun cuando todavía falta mucho camino por recorrer y avanzar, con el trabajo, por ejemplo, de la Corporación Humanas, del Observatorio de los Derechos Indígenas y, tal vez, aunque en un sentido ligeramente diferente, de la Red Iberoamericana de Jueces, junto con las ONGs chilenas históricas que han enfocado su trabajo a la lucha contra la impunidad respecto a las graves violaciones de derechos humanos ocurridas en Chile, incluyendo la Agrupación de Familiares de Detenidos Desaparecidos, CODEPU, y FASIC. Sin lugar a dudas, Chile requiere un mayor desarrollo de la asociatividad por los derechos humanos, forma elocuentemente eficiente de ejercicio del derecho humano a la participación, sobre todo en el ámbito del derecho del medio ambiente.

La cooperación entre el Defensor del Pueblo y las ONGs es vital para la acabada consecución de sus fines, ya que estas últimas se transforman en cruciales fuentes de información -alternativa a la información "oficial" proveniente de los organismos públicos- y de documentación y asesoría técnica. Sin perjuicio de proporcionar todo el respaldo que significa, muchas veces, el funcionamiento en redes de las ONGs en todo el mundo, que a su vez implica, fuentes de información y movimientos de presión más allá de las fronteras.

Una manifestación de la eficiencia y de la relevancia de las ONGs para la defensa de los derechos humanos es el caso Claude Reyes y otros vs. Chile, ante la Corte Interamericana de Derechos Humanos. En este caso, las ONGs Fundación Terram, ONG FORJA y la Corporación la Morada desarrollaron un papel impulsor decisivo. Las razones que motivaron este caso consisten en que, entre mayo y agosto de 1998, el Estado de Chile se negó a "brindar a los señores Marcel Claude Reyes, Sebastián Cox Urrejola y Arturo Longton Guerrero toda la información que requerían del Comité de Inversiones Extranjeras, en relación con la empresa forestal Trillium y el Proyecto Río Condor, el cual era un proyecto de deforestación que se llevaría a cabo en la Duodécima Región de Chile y "p[odía] ser perjudicial para el medio ambiente e impedir el desarrollo sostenible de Chile" 85 . La Corte finalmente resolvió, inter alia, que "[e]l Estado violó el derecho a la libertad de pensamiento y de expresión consagrado en el artículo 13 de la Convención Americana sobre Derechos Humanos, en perjuicio de los señores Marcel Claude Reyes y Arturo Longton Guerrero, en relación con las obligaciones generales de respetar y garantizar los derechos y libertades y de adoptar disposiciones de derecho interno esta- 
blecidas en los artículos 1.1 y 2 de dicho tratado, en los términos de los párrafos 61 a 103 de la presente Sentencia" ${ }^{\prime 6}$. Este es solo una pequeña muestra de muchos casos que han llegado al sistema interamericano gracias a la intervención activa de las ONGs de derechos humanos, lo cual demuestra una vez más el potencial del trabajo conjunto entre el Defensor y las ONGs.

Como se sabe, la intervención de las ONGs ha alentado el funcionamiento del sistema interamericano de protección de los derechos humanos, y una combinación del Defensor del Pueblo y las ONGs debiera dar un resultado incluso mejor. Esto mismo se puede decir de los resultados que se pueden obtener en el ámbito interno, de esta actuación conjunta, en beneficio de los derechos humanos, y particularmente, de un acceso más amplio y más eficiente a la justicia. El acceso a la justicia más amplio viene determinado porque las ONGs asumen la representación de derechos o intereses colectivos o difusos, tales como medio ambiente, o bien, por la posibilidad del Defensor del Pueblo de asumir la defensa de derechos e intereses de aquellos que no se pueden defender o lo hacen desde una posición de vulnerabilidad o desventajosa. Esta variante ya existe en América Latina en la Constitución argentina cuando señala que el Defensor del Pueblo "podrán interponer esta acción contra cualquier forma de discriminación y en lo relativo a los derechos que protegen al ambiente, a la competencia, al usuario y al consumidor, así como a los derechos de incidencia colectiva en general" 87 . Por su parte, la Constitución colombiana contempla dentro de las atribuciones del Defensor del Pueblo la de "invocar el derecho de Hábeas Corpus e interponer las acciones de tutela, sin perjuicio del derecho que asiste a los interesados" y de "interponer acciones populares en asuntos relacionados con su competencia" 88 . Por su parte, la Constitución de Venezuela señala que "la Defensoría del Pueblo tiene a su cargo la promoción, defensa y vigilancia de los derechos y garantías establecidos en esta Constitución y los tratados internacionales sobre derechos humanos, además de los intereses legítimos, colectivos y difusos, de los ciudadanos"89.

Dentro de este proceso de interacción e interrelación del Defensor con las ONGs puede ser un instrumento útil para canalizar denuncias de aquellos que no pueden hacerse escuchar por sí mismos, los invisibles o sin voz de nuestras sociedades actuales, incluyendo los migrantes legales e ilegales, refugiados, solicitantes de asilo, discapacitados, nińos en situación de calle, ancianos, detenidos y encarcelados, pueblos indígenas y minorías étnicas y religiosas.

Corte IDH: Caso Claude Reyes y otros vs. Chile. Fondo, Reparaciones y Costas. Sentencia de 19 de septiembre de 2006. Serie C No 151, par. 174, p. 64.

89 Artículo 280 de la Constitución de Venezuela de 1999. 
En este contexto de interacciones, el Defensor también debiera contemplar una asociación estratégica con Centros e Institutos de investigación en derechos humanos, incluso de carácter universitario, tanto a nivel interno como internacional, destacando, en este último aspecto, en el continente americano, el Instituto Interamericano de Derechos $\mathrm{Hu}-$ manos (adelante IIDH). Esta asociación estratégica podría permitir una colaboración en materia de cooperación y asesoría técnica, muchas veces necesaria para que el Defensor inicie sus investigaciones y lleve casos ante la justicia. No hay que dejar de lado tampoco, la capacitación técnica permanente de los funcionarios de la oficina del Defensor del Pueblo. En el caso particular del IIDH, cabe subrayar el rol clave en la creación y funcionamiento de la Federación Iberoamericana de Ombudsman.

\section{El CASO CHILENO: UN CASO ATÍPICO EN AMÉRICA LATINA}

En marzo del 2007, el Comité de Derechos Humanos manifestó su preocupación por la falta de una institución nacional de derechos humanos en Chile. En efecto, el Comité indicó que "[a]unque reconoce los esfuerzos del Estado Parte al respecto, el Comité observa con preocupación que una institución nacional de derechos humanos aún no ha sido establecida en Chile. (Artículo 2 del Pacto). El Estado Parte debería establecer cuanto antes una institución nacional de derechos humanos, plenamente en conformidad con los Principios relativos al Estatuto de las Instituciones Nacionales de Promoción y Protección de los Derechos $\mathrm{Hu}-$ manos (Principios de París), anexos a la resolución 48/134 de la Asamblea General. Con ese fin, debería realizar consultas con la sociedad civil" 90 . Esta recomendación ha sido formulada en términos similares en reiteradas ocasiones por otros órganos internacionales de vigilancia de tratados ${ }^{91}$.

$\mathrm{CDH}$ (2007) Observaciones finales del Comité de Derechos Humanos: Chile, CCPR/C/CHL/ $\mathrm{CO} / 5,17$ Abril, par.6.

91 "14. El Comité, aunque toma nota del proyecto de ley que se presentó al Congreso en 2003, expresa, como ya lo hizo en sus observaciones finales anteriores, su preocupación por la falta de una institución nacional de derechos humanos independiente que pueda ofrecer un mecanismo de denuncia y reparación accesible a los niños. 15. El Comité reitera su recomendación de que el Estado Parte establezca una institución de derechos humanos nacional independiente y que, a la luz de su Observación General No 2 sobre el papel de las instituciones nacionales independientes de derechos humanos en la promoción y protección de los derechos del niño (CRC/GC/2002/2) y los Principios de París (resolución 48/134 de la Asamblea General, anexo), extienda su presencia a todo el territorio nacional, en particular a las zonas más vulnerables, a fin de garantizar que todos los nińos puedan acceder fácilmente a ese mecanismo de denuncia independiente en caso de que se vulneren sus derechos; el Comité recomienda asimismo que se dote a esa institución de personal adecuadamente formado, capaz de atender dichas denuncias teniendo en cuenta la sensibilidad del niño." CDN (2007) Observaciones finales del Comité de los Derechos del Niño: Chile, CRC/C/CHL/CO/3, 23 de abril, par.14-15; CDESC (2004) Observaciones finales 
Desde el retorno progresivo de la democracia en Chile a principios de los ańos noventa, el tema de la creación de una institución nacional e independiente de derechos humanos ha sido arduamente debatido y negociado. Eso explica la razón por la cual se han presentado hasta la fecha varios proyectos de reformas constitucionales y legislativas sobre esta temática, sin ningún éxito aún. En este contexto, cabe subrayar el rol clave que ha venido desempeñando la organización no gubernamental del Capítulo Chileno del Ombudsman ${ }^{92}$.

En la actualidad, existe un proyecto de reforma constitucional a través del cual se intenta introducir la figura del Ombudsman o Defensor del Pueblo. Este proyecto de reforma ingresó, sin urgencia, al Congreso Nacional el 4 de diciembre de $2003^{93}$ y fue objeto de una indicación de parte de la Presidenta de la República el 10 de julio de $2007^{94}$. Con fecha 4 de junio de 2008, la Comisión de Derechos Humanos de la Cámara de Diputados aprobó el proyecto de reforma constitucional que crea la Defensoría de las Personas, el que fue remitido a la Sala de la Cámara de Diputados para su conocimiento y aprobación ${ }^{95}$. Con fecha 12 de junio de 2008, la Comisión de Constitución, Legislación y Justicia de la Cámara de Diputados solicitó a la Sala de la Cámara, le fuera remitido el proyecto aprobado por la Comisión de Derechos Humanos, para su conocimiento y debate y así fue resuelto por la Sala. A continuación examinaremos los principales aspectos de esta reforma.

En este complejo escenario, no se puede dejar de mencionar también el proyecto legislativo que crea el Instituto Nacional de Derechos Humanos. Una Comisión Mixta de diputados y senadores ha logrado aprobar un nuevo texto, que será sometido próximamente al Senado y a la Cámara de Diputados. El informe que contiene el texto del proyecto aprobado

del Comité de Derechos Económicos, Sociales y Culturales: Chile, E/C.12/1/Add.105, 26 de noviembre de par.31.

El Capítulo Chileno del Ombudsman- Defensor del Pueblo se fundó en 1985 en el seno del Grupo de Estudios Constitucionales (Grupo de los 24), organismo destinado a diseñar las bases constitucionales para el régimen democrático siguiente al gobierno militar. Entre ellas figuraba la creación del Defensor del Pueblo. Más información en: http://www.ombudsman.cl. Ver también Capítulo Chileno del Ombudsman (2008) Ocho puntos de propuestas y debate: para un proyecto legislativo sobre la Defensoría del Pueblo. Disponible en http://www.ambudsman.cl/pdf/8puntos_abr-2008.pdf

Boletín 3429-07.

94 En octubre de 2000, el Presidente de la República ingresó ante el Senado un proyecto de reforma constitucional que crea el Defensor del Ciudadano, para su examen por la Comisión de Constitución, Legislación, Justicia y Reglamento del Senado. Este proyecto fue retirado por el Poder Ejecutivo en noviembre de 2003. Todos los proyectos e indicaciones mencionados están disponibles en: http://www.ombudsman.cl

Informe de la Comisión de Derechos Humanos, Nacionalidad y Ciudadanía recaído en el proyecto de reforma constitucional que crea la Defensoría de las Personas, Boletín $\mathrm{n}^{\circ}$ 3429-07-1. 
por dicha Comisión lleva fecha 30 de junio de $2008^{96}$. El proyecto del Instituto no contempla la posibilidad de tramitar quejas de particulares, por consiguiente, este proyecto parece ser complementario al del Defensor de las Personas.

\section{Denominación}

Originalmente, en el proyecto de reforma constitucional se le había asignado a esta institución la denominación de Defensor del Ciudadano. Esta denominación con la que se había presentado esta institución al Parlamento merece comentarios y críticas. En efecto, por una parte, esta denominación restringe la actuación del Defensor, en materia de derechos humanos, al ámbito de los ciudadanos, categoría, esta última, que es limitada a un grupo específico de personas dentro del Estado, lo que atenta directamente contra el principio básico de cobertura universal en la protección y respeto de los derechos humanos. En este sentido, se han pronunciado diversos órganos de tratados tales como el Comité de Derechos Humanos, el Comité para la Eliminación de la Discriminación Racial, etc. Cabe recordar que todos los instrumentos internacionales de derechos humanos especifican que consagran derechos a todos los individuos que se encuentran en el territorio y bajo la jurisdicción del Estado parte ${ }^{97}$. Asimismo, el uso de la denominación ciudadano crearía la falsa impresión de que solo los ciudadanos gozan de derechos humanos dentro del territorio de un Estado, en circunstancias de que, de conformidad con los estándares internacionales y constitucionales, los derechos humanos rigen dentro del Estado para todos los individuos que se encuentren al interior del territorio. Esta es una consecuencia más del principio según el cual el Estado no proporciona ni otorga derechos humanos, sino que el individuo tiene derechos humanos por el solo hecho de serlo y derivado de su dignidad intrínseca. Finalmente, desde un punto de vista jurídico, como se sabe, dentro del orden interno existen categorías tales como ciudadano, nacional o extranjero e incluso apátrida, todos los cuales, desde el enfoque de los derechos humanos, tienen derechos y las instituciones del Estado, la obligación, de ver protegidos y amparados sus derechos

Informe de la Comisión Mixta, recaído en el proyecto de ley que crea el Instituto Nacional de Derechos Humanos, Boletín no 3.878-17: http://www.ombudsman.cl/pdf/info_com_ mix_inddhh.pdf

Por ejemplo, el Artículo 2(1) del Pacto Internacional de Derechos Económicos, Sociales y Culturales dispone lo siguiente: "Cada uno de los Estados Partes en el presente Pacto se compromete a adoptar medidas, tanto por separado como mediante la asistencia y la cooperación internacionales, especialmente económicas y técnicas, hasta el máximo de los recursos de que disponga, para lograr progresivamente, por todos los medios apropiados, inclusive en particular la adopción de medidas legislativas, la plena efectividad de los derechos aquí reconocidos". 
humanos al interior del territorio del Estado. En este sentido, como ya se ha dicho, la institución del Ombudsman o Defensor del Pueblo -según el modelo hispano y latinoamericano- tiene por objeto proteger a los individuos, grupos o pueblos frente a los actos realizados por los órganos o funcionarios de la administración del Estado, en el marco de sus facultades, en aquellos casos en que han excedido, abusado o mal usado sus atribuciones en perjuicio de los derechos humanos de los individuos, id est, cualquier individuo y cualquiera sea su estatus de acuerdo con el orden constitucional.

Exactamente en este sentido se ha pronunciado la doctrina nacional. Así, el profesor Nogueira ha señalado que "el sujeto objeto de protección no es el "ciudadano", que en el ámbito jurídico nacional es el "chileno mayor de 18 ańos y que no haya sido condenado a pena aflictiva" como lo indica el artículo 13 de nuestra Constitución, sino simplemente las personas, toda persona, cualquier persona que haya sido afectada en sus derechos por una institución privada o pública prestadora de servicios de utilidad pública o de satisfacción de necesidades públicas en el ámbito delimitado fijado por el proyecto de reforma constitucional. Así puede beneficiarse de la intervención del "Defensor del ciudadano" un nacional como una persona extranjera, un residente en Chile o una persona transeúnte, un mayor de edad o un menor de edad, una persona libre o un preso, no corresponde hacer en esta materia ninguna discriminación arbitraria y sin fundamento racional" 98 . En este mismo sentido, González ha sostenido que "no parece indiferente la denominación que se le asigne, pues ella, per se, podría dar un sesgo o significado, según la visión que se quiera remarcar, ya que, en estricto rigor, no es lo mismo decir 'Defensor del Ciudadano', 'Defensor del Pueblo', 'Defensor Cívico', 'Defensor del Hombre'. En verdad, todo me da a entender que estamos frente a un 'Defensor Ad hoc', nomenclatura que, por imprecisa, no es satisfactoria" 99 . Por su parte, en esta misma línea de razonamiento, el profesor Pfeffer ha señalado que "la denominación 'Defensor del Ciudadano' con que pretende incorporarse este organismo en nuestro ordenamiento jurídico no nos parece acertada. Ella induce a pensar que, lo que constituye un error, que solo un segmento de la población resultará protegido o tutelado por este organismo"100.

Nogueira Alcalá, Humberto (2001). "Las competencias para un "defensor del ciudadano" en Chile". Revista Ius et Praxis, núm. 1, pp. 443-460, especialmente, pp. 445-446.

González García, Hernán (2001). "Un defensor Ad hoc para Chile". Revista Ius et Praxis, núm. 1, pp. 461-467, especialmente, p. 463.

Pfeffer Urquiaga, Emilio, (2001). "Algunos criterios a considerar para la inserción del Defensor del Ciudadano en el ordenamiento jurídico nacional". Revista Ius et Praxis, núm. 1, pp. 523-533, especialmente, p. 524. 
Con todo, en julio del año 2007, el Gobierno de Chile presentó una indicación al proyecto a través de la cual, entre otras cosas, le cambió la denominación a la institución pasando a llamarse ahora Defensor de las Personas. En nuestra opinión, esta denominación también presenta debilidades. En primer lugar, "personas" tiene una significación muy precisa en el ordenamiento jurídico nacional, distinguiéndose entre personas naturales y personas jurídicas o morales. Salvo una jurisprudencia muy excepcional y focalizada en ciertos derechos, es comúnmente aceptado que los derechos humanos les pertenecen a los individuos, ya sea en su manifestación individual o colectiva. En otras palabras, solo los individuos, en su concreción individual o colectiva, gozan de derechos humanos. En consecuencia, la denominación de personas, confunde el objeto de la protección del Defensor, dejando también abierta aparentemente las puertas para las personas jurídicas. Esta distinción entre el individuo en su manifestación individual y colectiva, nos permite mencionar una segunda debilidad en la denominación. Esta consiste en que persona alude a la individualidad del ser humano, pero no comprende la colectividad de este último. Esto se aprecia como un problema porque ambas manifestaciones del ser humano, la individual y la colectiva, gozan de derechos humanos, individuales y colectivos. Por tanto, personas, al no considerar la vertiente colectiva del individuo podrían dejar fuera del ámbito de protección a los derechos colectivos. Finalmente, no debe dejar de tenerse presente que la sociedad americana y la chilena en particular, son sociedades multiculturales y multiétnicas, con un fuerte componente de minorías, de grupos afrodescendientes y, especialmente, de pueblos indígenas, cuyos derechos humanos son eminentemente colectivos. En consecuencia, con la denominación de personas, todos estos grupos, comunidades y pueblos quedarían fuera de la protección y amparo del Defensor. Por esta razón, nuestra propuesta -nada novedosa por lo demás- es optar por la denominación más acabada y comprensiva, consistente en el Defensor del Pueblo, ya que este está compuesto por el colectivo y por cada uno de los miembros que lo integran y además que hace referencia al modelo iberoamericano del Ombudsman. Resulta difícil de entender porque las autoridades chilenas involucradas en este tema son tan reacias en usar ese término, que ha sido usado por otros países latinoamericanos sin gran dificultad.

Ahora bien, parece que más allá del nombre de la institución, según el objetivo expresado en el proyecto de reforma constitucional de acuerdo con la indicación presentada por el Ejecutivo en julio de 2007, se estaría otorgando esta posibilidad de incluir la manifestación individual y colectiva de las personas. En efecto, en la Indicación al Proyecto de 10 de julio de 2007 (en adelante la Indicación) se señala que el Defensor "velará por la defensa de los derechos y garantías establecidos en la Constitución Política del Estado y en los tratados internacionales suscritos y ratificados 
por Chile", sin aludir al sujeto concreto de la defensa ${ }^{101}$. Sin embargo, debe tenerse presente que lamentablemente en el Proyecto Original de 4 de diciembre de 2003 (en adelante el Proyecto Original) era mucho más explícito al respecto y decía que el Defensor "velará por la defensa y promoción de los derechos e intereses de las personas [...] y le corresponderá también difundir y promover los derechos y garantías establecidos en el artículo 19 y asumir la defensa de aquellos que tengan impacto colectivo o involucren a una pluralidad de individuos"102. Esta frase final, que fue desgraciadamente eliminada del proyecto por la indicación de 2007, permitía incluir dentro de la actuación del Defensor, los derechos e intereses colectivos, e incluso los difusos. Con todo, como se ha reiterado, a lo largo de este artículo, nosotros mantendremos la denominación de Defensor de Pueblo, toda vez que nos parece la más acertada y refleja de mejor manera el sentido y alcance de los derechos que el Defensor debiera tender a proteger.

\section{Nombramiento}

La forma de la designación del Defensor del Pueblo (de las Personas) es crucial. Evidentemente, esto determina, por un lado, la independencia fáctica del nombrado en el cargo y, por otro, el perfil necesariamente técnico y altamente valorado del Defensor. Naturalmente, el Defensor debe ser una persona de reconocido prestigio, ampliamente reputado a nivel nacional e internacional y, particularmente, entre los grupos y las ONGs vinculadas a los derechos humanos. Estas agrupaciones incluyen organizaciones medioambientales, de desarrollo, de lucha contra la pobreza, de defensa de minorías y de pueblos indígenas, etc. Todas estas organizaciones deben dar cuenta del más amplio rango de representaciones de derechos e intereses dentro del país. Consecuentemente, el equipo de trabajo del Defensor debería tener primordialmente un perfil técnico-valórico. El Defensor debería gozar del respaldo, pero sobre todo de la confianza de todo el pueblo y para ello se requiere lograr el consenso -y recabar la participación por tanto- de todas las agrupaciones u organizaciones que actúen en derechos humanos dentro del país.

La sola intervención del Poder Ejecutivo y/o del Poder Legislativo en el proceso de nombramiento del Defensor es insuficiente, tal como lo indican expresamente los Principios de París. En efecto, desde el punto de vista del nombramiento, Julio Estrada ha señalado que "aunque el modelo arquetípico de la institución, el escandinavo, prevé que el nombramien-

101 Artículo 100 A, Indicaciones al Proyecto de Reforma Constitucional que crea el Defensor del Ciudadano (Boletín No 3429-07), de fecha 10 de julio de 2007.

102 Artículo 89 A, Proyecto de Reforma Constitucional que crea el Defensor del Ciudadano, de fecha 4 de diciembre de 2003. 
to del Ombudsman sea hecho por la Cámara sin intervención del Poder Ejecutivo, otros ordenamientos contemplan la participación de ambos poderes en la designación, y algunos atribuyen esta facultad únicamente al Ejecutivo sin intervención alguna de la legislatura. Se ha querido ver el nombramiento hecho por el Poder Legislativo una garantía de la independencia de la institución; sin embargo, dicha independencia y autonomía provienen de un conjunto de factores y no exclusivamente de cuál es la autoridad encargada de nombrarlo"103. Así, en el Proyecto Original se contemplaba que el Defensor fuera "nombrado por el Presidente de la República con acuerdo de la Cámara de Diputados, adoptado por la mayoría de sus miembros en ejercicio en sesión especialmente convocada al efecto"104. La Indicación añadió una ligera modificación al señalar que el Defensor sería "nombrado por el Presidente de la República de una terna presentada por acuerdo de la Cámara de Diputados, adoptado por dos tercios de sus miembros en ejercicio, en sesión especialmente convocada al efecto"105. En ambos casos interviene el Poder Ejecutivo y el Poder Legislativo. Lamentablemente, no se contempla la participación de la sociedad civil organizada. En ambos casos, es el Presidente de la República el que nombra, lo cual puede representar un problema ya que este es el jefe de la administración a la que, inter alia, el Defensor está llamado a controlar. La intervención de la Cámara de Diputados también puede representar un problema real. Si bien, la intervención de la Cámara de Diputados puede significar la intervención democrática en el nombramiento, en el sentido de la mayoría, del mismo modo, puede implicar la politización del nombramiento del Defensor, lo cual se traduciría en el fracaso de la institución. Las lealtades con el sector que lo propone o nombra probablemente repercutirán en una eficacia relativa de la institución a la hora de efectuar una fiscalización a dichas personas. Respecto a la intervención del Ejecutivo, Ríos ha seńalado que la designación por parte del Presidente de la República "vulnera la esencia de esta institución. No se concibe que el jefe supremo de la Administración del Estado designe al funcionario encargado de fiscalizarla [...]. Si el Defensor del Ciudadano ha de ser 'mandatario o representante del parlamento' a fin de 'controlar la actividad de Administración', como reconoce el proyecto refiriéndose a sus orígenes, lo lógico y congruente es que sea designado por el Congreso y que ante él deba rendir cuenta del desempeño de su función"106.

Julio Estrada, Alexei (1994) 52.

fecha 4 de diciembre de 2003.

105 Artículo $100 \mathrm{C}$, Indicaciones al Proyecto de Reforma Constitucional que crea el Defensor del Ciudadano (Boletín No 3429-07), de fecha 10 de julio de 2007.

106 Ríos Álvarez, Lautaro (2001). "El nombramiento del Defensor del Ciudadano", Revista Ius et Praxis, núm. 1, pp. 491-504, especialmente, pp. 501-502. 
Una de las características que debería reunir el Defensor del Pueblo para ser nombrado es gozar de una gran reputación e idoneidad ampliamente reconocida en todos los sectores políticos y sociales, y sobre todo, en la opinión pública informada. El Defensor, por supuesto, desde un punto de vista técnico debería poseer las cualidades necesarias en el ámbito de la protección de los derechos humanos de los individuos, grupos y pueblos. Además, el Defensor debe estar dotado de excelentes cualidades comunicacionales ya que se encuentra en excelente posición para convertirse en un mediador -sobre todo en afectaciones a los derechos humanos derivadas de actuaciones de la Administración del Estado- y un mediador es indudablemente un negociador. En este sentido, Parejo Alfonso, refiriéndose al caso espańol, ha dicho que "[d]adas las características del Defensor del Pueblo, su utilización al servicio de fórmulas de solución (vía mediación y composición) de los 'contenciosos gubernativos', por emplear una vieja expresión e, incluso, de procedimientos especialmente complejos y con implicación de múltiples intereses (por ejemplo, y típicamente, los medioambientales) constituiría, sin duda, una buena experiencia para la progresiva renovación de nuestro sistema administrativo"107.

Sin duda, otro elemento que resulta un buen indicador para un desempeńo independiente, imparcial y eficaz del Defensor u Ombudsman es su forma de nombramiento. En general, sobre todo en el caso de la figura clásica del Ombudsman, es decir, el controlador del buen desempeńo de las administraciones públicas, el nombramiento se hace por el Parlamento u órgano legislativo, pero en ciertos casos realmente remarcables, como la situación del Ombudsman de la ciudad de Nueva York, el cargo es elegido por votación popular, lo cual es un factor de aseguramiento de la independencia, neutralidad y transparencia en el cumplimiento de sus funciones ${ }^{108}$.

Dentro de los requisitos que es necesario e indispensable que el Defensor del Pueblo reúna en el desarrollo de su labor es la protección y aseguramiento de ciertos privilegios, tales como la confidencialidad en la documentación y el tratamiento de la información que reciba, de otro modo, la eficacia de su función se vería altamente comprometida. En este sentido, Kuta ha claramente señalado que "estos privilegios y confidencialidades son cruciales para el efectivo uso de los servicios del Ombudsman"109. 


\section{Autonomía respecto del gobierno y del parlamento}

El Defensor del Pueblo debe ser independiente y gozar de la más amplia y total autonomía en cumplimiento de su misión y en la satisfacción de sus funciones. Justamente, la importancia de su misión justifica la necesidad de dotar lo de amplia autonomía. Independientemente de quién lo nombre, el Defensor debe permanecer al margen de cualquier supuesta lealtad o sometimiento. También es crucial que se garantice constitucionalmente al Defensor el amparo frente a cualquier intento de presión o manipulación por parte del Parlamento o el Gobierno.

En España, por ejemplo, la Ley Orgánica del Defensor del Pueblo (LODP) garantiza la autonomía del Defensor, declarando que "no estará sujeto a mandato imperativo alguno", que "no recibirá instrucciones de ninguna autoridad" y que "desempeñará sus funciones con autonomía y según su criterio" 110 . Por su parte, el artículo 86 de la Constitución argentina señala que "[e]l Defensor del Pueblo es un órgano independiente instituido en el ámbito del Congreso de la Nación, que actuará con plena autonomía funcional, sin recibir instrucciones de ninguna autoridad". Otro ejemplo notable lo constituye el caso de Bolivia, cuya Constitución, en el artículo 127, contiene una norma similar, protectora de la autonomía e independencia del Defensor del Pueblo, consistente en que "[e]l Defensor del Pueblo no recibe instrucciones de los Poderes públicos”.

\section{Mandato amplio basado en normas universales de derechos hu- manos}

El proyecto que crea el Defensor es criticado también con toda razón por el mal diseńo o las escasas atribuciones que se le otorgan en el ámbito de los derechos humanos. Así por ejemplo, Suárez considera que "[e]s un defecto del proyecto no establecer un papel más proactivo en la defensa de los derechos humanos, habilitándolo por ejemplo: a) Para proponer al Presidente de la República la suscripción de convenios o acuerdos internacionales en materia de derechos humanos, b) Para elaborar y ejecutar programas preventivos en el mismo ámbito, c) Para ejercer un papel más preeminente en la mediación de conflictos entre individuos y los grupos y la Administración o, d) Para cumplir, incluso, sin perjuicio de las atribuciones de la Contraloría General de la República, un papel preventivo de la legalidad de los actos de la Administración, precaviendo con antelación al Presidente de la República sobre la probable inconstitucionalidad o ile-

110 Sainz Moreno, Fernando (1992): "Defensor del Pueblo y Parlamento". En VV.AA.: Diez años de la Ley Orgánica del Defensor del Pueblo. Problemas y Perspectivas. Universidad Carlos III, Madrid, pp. 5-70, especialmente, p. 57; Artículo 6. Ley Orgánica 3/1981, de 6 de Abril, del Defensor del Pueblo. 
galidad de su actuación"111. Además de estas atribuciones que sugiere el profesor Suárez, las que compartimos, pensamos que el Defensor del Pueblo o de las Personas - designación que propone la Indicación- debería tener la facultad de supervisar el cumplimiento de las resoluciones de los tribunales internacionales de derechos humanos, por ejemplo, de la Corte Interamericana de Derechos Humanos (en adelante la Corte I.D.H.). En este sentido, conviene tener presente que las sentencias de la Corte I.D.H. son obligatorias y ejecutorias de acuerdo con lo que dispone el artículo 68 de la Convención Americana de Derechos Humanos ${ }^{112}$.

En el Proyecto Original se señalaba que el Defensor velaría "por la defensa y promoción de los derechos e intereses de las personas ante actos u omisiones de los órganos de la Administración del Estado, en lo relativo a la satisfacción de las necesidades públicas"113. En la Indicación se expresa que el Defensor "velará por la defensa de los derechos y garantías establecidos en la Constitución Política del Estado y en los tratados internacionales suscritos y ratificados por Chile, ante actos $\mathrm{u}$ omisiones de los órganos e instituciones responsables de la satisfacción de las necesidades públicas"114. En ambos casos, como es normal, la actuación del Defensor se puede desencadenar por actos $\mathrm{u}$ omisiones. Pero, en el primer caso se trataba de actos emanados de los órganos de la Administración del Estado mientras que en el segundo, se refiere a actos de los órganos e instituciones responsables de la satisfacción de las necesidades públicas. En el Proyecto Original se le asignaba al Defensor la labor de "defender y promover los derechos e intereses de las personas" y en la Indicación la tarea es tan solo defender los "derechos y garantías establecidos en la Constitución Política del Estado y en los tratados internacionales suscritos y ratificados por Chile".

\section{Luces y sombras del caso chileno}

Sin duda, la institución de la Defensoría del Pueblo o de la Persona sería un aporte para la protección y respeto de los derechos humanos de individuos, grupos y pueblos en Chile, ya que con ella se tendría un nuevo mecanismo de control de las actuaciones de los órganos administrativos del Estado frente a los sujetos que resulten afectados en sus dere-

111 Suárez Crothers, Christian (2001) 572.

112 "Los Estados Partes en la Convención se comprometen a cumplir la decisión de la Corte en todo caso en que sean partes". Artículo 68.1. de la Convención Americana de Derechos Humanos; El Estado de Chile se encuentra obligado por esta Convención, ya que la ratificó con fecha 8 de octubre de 1990.

113 Artículo 89 A, Proyecto de Reforma Constitucional que crea el Defensor del Ciudadano, de fecha 4 de diciembre de 2003.

114 Artículo $100 \mathrm{~A}$, Indicaciones al Proyecto de Reforma Constitucional que crea el Defensor del Ciudadano (Boletín No 3429-07), de fecha 10 de julio de 2007. 
chos por abusos de dichos órganos. Así, el Defensor se transforma en un controlador del ejercicio del poder y, eventualmente, en un represor del ejercicio abusivo, ilegal o inconstitucional del poder en perjuicio de los individuos o grupos débiles, despojados o vulnerables. En este sentido, Monti señala que el Defensor debe desarrollar una labor "conductora de los problemas sociales, vocero de los que no pueden hacerse oír, y creador imaginativo de soluciones"115. En esta línea, incluso en el continente americano, existió un antecedente histórico con la Procuraduría de los pobres, en México, en $1848^{116}$. En este sentido, el Defensor se inserta en plenitud en la raison d'être de los derechos humanos, cual es, proteger y amparar a los desvalidos, débiles o vulnerables. Este es, por lo demás, el alcance en su mayor amplitud del constitucionalismo contemporáneo del Estado social y democrático de derecho. Por eso Pérez Royo ha señalado que Estado social es "un Estado comprometido con la promoción del bienestar de la sociedad y de manera muy especial con el de aquellos sectores menos favorecidos de la misma"117. En esta línea, Nogueira ha seńalado, correctamente a nuestro entender, que "el Defensor del Ciudadano o de la persona llena un vacío institucional existente en forma permanente en nuestra historia republicana, el del defensor de los débiles, desorganizados, desamparados, respecto de sus derechos, no solo a tener servicios de parte de la administración o de instituciones privadas dedicadas a brindar servicios públicos, de utilidad pública o a la satisfacción de necesidades públicas, sino también ser un vehículo catalizador para superar el irrespeto de los derechos fundamentales de aquellos que por ignorancia, lejanía, falta de recursos, no pueden hacer frente a las acciones $\mathrm{u}$ omisiones atentatorias de derechos fundamentales"118. Este es justamente el caso de los nińos, pobres o ancianos o de internos en hospitales psiquiátricos o situación de reclusos o privados de libertad en cárceles. Maiorano ha magistralmente reflejado esto último cuando ha seńalado que el Defensor del Pueblo debe "estar comprometido con una visión más justa de la sociedad que permita la dignificación del ser humano y actuar sobre los factores que distorsionan los valores de una comunidad. Debe ser un innovador, casi un rebelde con causa [...] es una institución que debe actuar con objetividad, pero con parcialidad. Es quien convive con la injusticia generada por los excesos o abusos del poder público y del poder privado, económico en

\footnotetext{
115 Monti, Eduardo Jorge. 31.

116 Castrejón García, Gabino E. (2007): "El Ombudsman como órgano de control constitucional de la administración pública", En Cisneros Farías, Germán; Fernández Ruiz, Jorge y López Olivera, Miguel Alejandro (Coord.). Ombudsman local. Segundo Congreso Iberoamericano de Derecho Administrativo. México: Instituto de Investigaciones Jurídicas de México, México, pp. 79-89, especialmente, p. 80.

117 Pérez Royo, Javier (2001): "Estado social de derecho". En Aragón Reyes, Manuel (Coord.). Temas básicos de Derecho Constitucional. Tomo I, Madrid: Civitas, p. 162.

118 Nogueira Alcalá, Humberto (2001) 444.
} 
la especie, no puede permanecer distante ni imparcial ante esa situación [...] debe ponerse en los zapatos del quejoso; debe asumir la posición del insatisfecho, del descreído, del desesperanzado, de aquel cuyos derechos humanos han sido desconocidos, por acción u omisión..." 119 .

La importancia del Defensor en la protección de los derechos humanos de los grupos vulnerables, excluidos y marginalizados es amplificada por el hecho de la total ignorancia de los individuos y grupos de sus propios derechos y de los mecanismos de control y protección de los mismos. En definitiva, en este contexto, el Defensor representaría una segunda etapa en el proceso evolutivo y expansivo de los derechos humanos. En efecto, un primer paso en el proceso de desarrollo de los derechos humanos ha sido el reconocimiento de los derechos, mientras que la creación de una institución que procure el respeto y protección de los derechos humanos de los vulnerables o débiles y su posterior empoderamiento, constituiría un segundo paso.

A nuestro entender, es necesario precisar que no cabe reducir esta institución del Defensor a un mecanismo de control contencioso-administrativo o que permita resolver controversias contencioso-administrativas, como parece desprenderse de las palabras de Pfeffer cuando seńala, a propósito del Defensor, que en el país existe una "[...] carencia de procedimientos y tribunales que conozcan de los asuntos contenciosoadministrativos, lo que justifica y hace urgente la existencia de este nuevo mecanismo. Este instituto está llamado a llenar un vacío importante en esta materia"120. En esta referencia, se deja entrever la visión clásica del Defensor del Pueblo o de las Personas, ya que se hace directa alusión a la actuación de la Administración del Estado. En efecto, Pfeffer vuelve a reiterar que la creación de esta institución "[...] permitirá mejorar el desempeño funcionario, la atención de público, disminuirá los tiempos de los trámites, los malos tratos, entre otras ventajas"121. Una posición más cauta, pero también dentro de la visión clásica del rol del Defensor del Pueblo o de las Personas, nos plantea Suárez, cuando señala que "[...] el exceso de control desincentiva un quehacer administrativo eficiente y eficaz. [...]. El exceso de control sobre el funcionario haría de este un personaje pusilánime, poco creativo [...] más preocupado, en realidad, de cumplir con la mediocridad de las pautas impuestas que de atender a la solución del problema que se ha colocado en sus manos"122.

La participación del pueblo y por tanto, el ejercicio y goce del derecho a la participación consagrado en el artículo 25 del Pacto Internacional de Derechos Civiles y Políticos, también se ve notablemente beneficiada y 
potenciada con la institución del Defensor. En efecto, a través de la labor de control de la Administración del Estado, en cuanto se podrán hacer públicos -a través de los informes que debe preparar la Defensoría- los abusos que se cometan en el cumplimiento de las labores del aparato estatal. Esta última situación debería incidir en una mejoría en el estándar de funcionamiento de la Administración del Estado. En el fondo, el Defensor-como representante del pueblo- mejora el ejercicio y control democrático, pero no solo del gobierno sino de todos los órganos del Estado. Relevante en este sentido, es que, según Aguiar de Luque, los informes del Defensor español "constituyen algo así como una radiografía social de España" 123 . Además, en el caso de la Comisión Nacional de Derechos Humanos de México, se ha dicho que "a semejanza del modelo clásico, las recomendaciones que emita la Comisión no tienen un carácter vinculante, y por lo tanto no son de obligatorio cumplimiento por la autoridad o servidor público a quien se dirija; tampoco anula o modifica el acto administrativo censurado. Su fuerza radica principalmente en la publicidad de que gozan" 124 .

Sin embargo, no todo son luces en la creación de esta institución. También aparecen resaltadas ciertas dificultades. En efecto, el proyecto del Defensor del Pueblo presenta también complejidades que no se pueden soslayar. Tal como ha sido sostenido por Milos, los obstáculos para avanzar están constituidos por "[...] Una voluntad política consistente que siga a los proyectos enviados por el Ejecutivo, de parte de los partidos que lo apoyan y, [...] se observa reticencia de los sectores políticos de oposición, e incluso de Gobierno; [...] [la ausencia de] una vinculación con las organizaciones y movimientos ciudadanos, lo que unido a la ausencia de una estrategia comunicacional, no ha permitido su conocimiento, la participación y el apoyo ciudadano; [...] Las iniciativas del Ejecutivo han encontrado resistencia, de orden político, a dar cabida en nuestro sistema institucional a una nueva figura, autónoma e independiente, que fortaleciera formas de expresión ciudadana eventualmente críticas del sistema de representación existente y que pudieran incluso dar lugar a protagonismos en la sociedad política"125. Con todo, a pesar que el proceso pueda estar ensombrecido por ciertas dificultades, ello no mella la extraordinaria relevancia que tiene el Defensor del Pueblo pasando a constituirse en una necesidad, como se verá a continuación, dentro de una sociedad democrática, para la protección de los derechos humanos.

\footnotetext{
123 Aguiar de LuQue, Luis (2001) 231.

124 Julio Estrada, Alexei (1994) 55.

125 Mrlos, Juan Domingo (2001). "Finalidad y competencias del Defensor del Ciudadano". Revista Ius et Praxis, núm. 1, pp. 469-481, especialmente, p. 470.
} 


\section{CONCLUSIONES}

1. Sin duda que uno de los factores que ha convertido al Defensor del Pueblo en una institución estructural del constitucionalismo contemporáneo reside en que es una institución de defensa de los derechos humanos y los derechos humanos se encuentran en el corazón del constitucionalismo social y democrático de derecho.

2. Los derechos humanos que defiende, por imperativo constitucional, y de acuerdo a los valores supremos que se encuentran en la Constitución, como el bien común -el bienestar de toda la comunidad sin exclusiones-, son los derechos de aquellos vulnerables, los despojados, débiles o desvalidos.

3. El defensor del pueblo se configura como una institución relevante para hacer una realidad la aplicación en el orden doméstico tanto del Derecho Constitucional como Derecho Internacional de los derechos humanos. En este sentido, debe destacarse el principal rol que puede jugar el Defensor del Pueblo en el foro doméstico para revelar la trascendencia de los instrumentos y estándares internacionales de derechos humanos, en particular, en aquellas áreas más débiles de cumplimiento por parte de la Administración del Estado, tales como los derechos económicos, sociales y culturales como en el área de los derechos colectivos y medioambientales.

4. En este rol, el Defensor del Pueblo puede llegar a cumplir un papel trascendente en la cooperación con los órganos de tratados de derechos humanos, tanto en el orden regional como internacional. Tanto en la etapa de formulación de los informes, como en la etapa de seguimiento y cumplimiento de las recomendaciones contenidas en las Conclusiones Finales para el Estado.

5. Tampoco debe dejarse de mencionar que las ONGs pueden jugar el rol de un relevante socio del Defensor del Pueblo y, a su vez, la existencia del Defensor del Pueblo, como institución nacional de derechos humanos, puede contribuir a estimular el surgimiento de ONGs preocupadas de los derechos humanos y del bienestar de individuos, grupos y pueblos.

\section{BIBLIOGRAFÍA}

- Abad Amoros, Ma Rosa (2000). "El Recurso de Inconstitucionalidad del Defensor del Pueblo contra la LO 15/99 de Protección de Datos de Carácter Personal". REDI Revista Electrónica de Derecho Informático, Núm. 28, pp. 1-14. 
- Aguiar de Luque, Luis (2001): "Defensor del Pueblo". En Aragón Reyes, Manuel (Coord.). Temas básicos de Derecho Constitucional, Tomo III, Madrid: Civitas, pp. 228-232.

- Alarcón, Arthur L. (2007). "A Prescription for California's Ailing Inmate Treatment System: An Independent Corrections Ombudsman". Hastings Law Journal, $\mathrm{N}^{\circ}$ 58, pp. 591-621.

- Anderson, Stanley V. (1983). "The Corrections Ombudsman in the United States". Int'l Handbook of the Ombudsman, 137, p. 143.

- Brewer-Carias, Allan (2005) Mecanismos nacionales de protección de los derechos humanos (Garantias judiciales de los derechos humanos en el derecho constitucional comparado latinoamericano), Instituto Interamericano de Derechos Humanos, San José, Costa Rica.

- Briceño Vivas, Gustavo (1995) Un Ombudsman para la democracia, Editorial Biblioteca Jurídica Dike, Medellín: $1^{a}$ edición.

- Cancado Trincade, Antonio A. (2008) El Derecho de acceso a la justicia en su amplia dimensión, Santiago de Chile: Editorial Librotecnia.

- Carrillo Salcedo, Juan Antonio (1996) Soberanía de los Estados y derechos humanos en Derecho Internacional contemporáneo. Madrid: Tecnos.

- Castrejón García, Gabino E. (2007): "El Ombudsman como órgano de control constitucional de la administración pública". En Cisneros Farías, Germán, Fernández Ruiz, Jorge y López Olivera, Miguel Alejandro (Coord.). Ombudsman local. Segundo Congreso Iberoamericano de Derecho Administrativo. México: Instituto de Investigaciones Jurídicas de México, pp. 79-89.

- Cisneros Farías, Germán (2007): "Reflexiones sobre el establecimiento del Ombudsman de los niños. Concepto y tareas especificas". En Cisneros farías, Germán, Fernández Ruiz, Jorge y López Olivera, Miguel Alejandro (Coord.). Ombudsman local. Segundo Congreso Iberoamericano de Derecho Administrativo. Instituto de Investigaciones Jurídicas de México, México, pp. 143-149.

- Claude, Richard P. (1976) Comparative Human Rights. Baltimore: John Hopkins University Press.

- Cominelli, Luigi (2002). "An Ombudsman for the Europeans: Gradually Moving towards "Effective Dispute Resolution" Between Citizens and Public Administrations". The International Ombudsman Yearbook, volume 6, pp. 143-182.

- Cruz Villalón, Pedro (2001): "Protección jurisdiccional de los derechos fundamentales". En Aragón Reyes, Manuel (Coord.). Temas básicos de Derecho Constitucional. Tomo I, Madrid: Civitas, pp. 226-228.

- Fitzgerald, Oonagh E. (Ed.) (2006) The Globalized Rule of Law: Relationships Between International and Domestic Law, Toronto: Irwin Law. 
- González García, Hernán (2001). "Un defensor Ad hoc para Chile". Revista Ius et Praxis, núm. 1, pp. 461-467.

- Green, Mark y Eisner, Laurel W. (1998). "The Public Advocate for New York City: An Analysis of the Country's Only Elected Ombudsman". New York Law School Law Review, N 42, pp. 1093-1161, especialmente, p. 1104.

- Instituto Interamericano de Derechos Humanos (2003) Promoción y defensa de los derechos reproductivos: nuevo reto para las institucionales nacionales de derechos humanos, San José, Costa Rica.

- Islas Colin, Alfredo e Islas Colin, Marco Antonio (2007): "El Ombudsman: control no jurisdiccional y protección de derechos humanos". En Cisneros Farías, Germán, Fernández Ruiz, Jorge y López Olivera, Miguel Alejandro (Coord.). Ombudsman local. Segundo Congreso Iberoamericano de Derecho Administrativo, México: Instituto de Investigaciones Jurídicas de México, pp. 179-205.

- Julio Estrada, Alexei (1994) El Ombudsman en Colombia y en México: una perspectiva comparada, México: Universidad Nacional Autónoma de México.

- Kelsen, Hans (1977) Esencia y valor de la democracia. 2a edición, Madrid: Labor.

- Kuta, Christina M. (2003). "Universities, Corporations and States use them - Now It's Time to Protect them: an Analysis of the Public and Private Sector Ombudsman and the Continued Need for a Privileged Relationship". Southern Illinois University Law Journal, № 27, pp. 389-412.

- Lorenzetti, Ricardo (2000) "Daños masivos, acciones de clase y pretensiones de operatividad", en Jurisprudencia Argentina 7 de junio de 2000.

- Maiorano, Jorge Luis (1998). "El defensor del Pueblo de la Nación: su función tutelar en el ámbito de la regulación económica”. Revista Jurídica de Buenos Aires, vol. III, pp. 69-79.

- Méndez Pinedo, Elvira (1998) La protección de consumidores en la Unión Europea: hacia un derecho procesal comunitario de consumo, Madrid: Marcial Pons.

- Milos, Juan Domingo (2001). "Finalidad y competencias del Defensor del Ciudadano". Revista Ius et Praxis, núm. 1, pp. 469-481.

- Monti, Eduardo Jorge. "El Ombudsman: ¿Por qué? y ¿Para qué?”. Verba Iustitiae, Revista de la Facultad de Derecho, Ciencias Políticas y Sociales, Universidad de Morón, Año X, No 20, pp. 31-58.

- Mugica Herzog, Enrique (2006) Defensor del Pueblo: el modelo iberoamericano. Conferencia del Defensor del Pueblo, Excmo. Sr. Don Enrique Mugica Herzog, en la XIX edición del curso Postgrado en Derecho Constitucional, Universidad de Salamanca, Salamanca, p. 2. 
- Nogueira Alcalá, Humberto (2001). "Las competencias para un "defensor del ciudadano" en Chile". Revista Ius et Praxis, núm. 1, pp. 443-460.

- OACNUDH, Manual sobre la creación y el fortalecimiento de instituciones nacionales para la promoción y protección de los derechos humanos, 1996, Disponible en: www.ohchr.org/Documents/Publications/ training4en.pdf

- OANUDH, Los derechos económicos, sociales y culturales, Manual para las instituciones nacionales de derechos humanos, Serie de Capacitación Profesional No 12, Nueva York y Ginebra, 2004, Disponible en: www.ohchr.org/Documents/Publications/training12sp.pdf

- OACNUDH, Folleto informativo No 19, Instituciones Nacionales de Promoción y Protección de los Derechos Humanos, Ginebra, Suiza, Disponible en: http://www.ohchr.org/Documents/Publications/FactSheet 19sp.pdf

- OACNUDH, Folleto Informativo No.30, El Sistema de Tratados de Derechos humanos de las Naciones Unidas, Ginebra, Suiza, Disponible en: http://www.ohchr.org/Documents/Publications/FactSheet30sp.pdf

- Parejo Alfonso, Luciano (1992): "El Defensor del Pueblo como institución de control de la Administración Pública”. En VV.AA.: Diez años de la Ley Orgánica del Defensor del Pueblo. Problemas y Perspectivas, Madrid: Universidad Carlos III, pp. 103-132.

- Pérez Calvo, Alberto (1996): "Artículo 54: El defensor del pueblo", en Alzaga Villamil, Oscar (Coord.). Comentarios a la Constitución Española, 2a edición, Tomo IV, Madrid: Edersa, pp. 531-579.

- PÉrez Royo, Javier (2001): "Estado social de derecho". En Aragón Reyes, Manuel (Coord.). Temas básicos de Derecho Constitucional. Tomo I, Madrid: Civitas, pp. 162-164.

- Pfeffer Urquiaga, Emilio (2001). "Algunos criterios a considerar para la inserción del Defensor del Ciudadano en el ordenamiento jurídico nacional". Revista Ius et Praxis, núm. 1, pp. 523-533.

- Ríos Álvarez, Lautaro (2001). "El nombramiento del Defensor del Ciudadano". Revista Ius et Praxis, núm. 1, pp. 491-504.

- Sainz Moreno, Fernando (1992): "Defensor del Pueblo y Parlamento". En VV.AA. Diez años de la Ley Orgánica del Defensor del Pueblo. Problemas y Perspectivas, Madrid: Universidad Carlos III, 1992, pp. 5-70.

- Suárez Crothers, Christian (2001). "¿Tiene alguna justificación la introducción del Ombudsman en el ordenamiento jurídico chileno?". Revista Ius et Praxis, núm. 1, pp. 559-574.

- UNICEF INNOCENTI RESEARCH CENTRE (2001), Independent Institutions Protecting Children's Rights, Innocenti Digest, No 8 . 
- UNICEF INNOCENTI RESEARCH CENTRE (2006) The General Measures of the Convention on the Rights of the Child: The Process in Europe and Central Asia, 2006, pp.17-25.

- Valladares, Leo (2000) El Ombudsman como cana de acceso a la justicia. Disponible en: www.juridicas.unam.mx/publica/librev/rev/ iidh/cont $/ 32 / \mathrm{pr} / \mathrm{pr} 3 . \mathrm{pdf}$ 